\title{
Modeling and Simulation of an Indirect Natural Convection Solar Dryer with Thermal Storage Bed
}

\author{
Benjamin Ternenge Abur \\ Department of Mechanical/Production Engineering, Abubakar Tafawa Balewa University, Bauchi-Nigeria \\ E-mail address: engrbenjaminabur@gmail.com \\ Habou Dandakouta \\ Department of Mechanical/Production Engineering, Abubakar Tafawa Balewa University, Bauchi-Nigeria
}

\author{
Adisa A. B \\ Department of Mechanical/Production Engineering, Abubakar Tafawa Balewa University, Bauchi-Nigeria \\ Ejilah R.I. \\ Department of Mechanical/Production Engineering, Abubakar Tafawa Balewa University, Bauchi-Nigeria.
}

Received: 15 April 2020; Accepted: 13 May 2020; Published: 08 August 2020

\begin{abstract}
The intermittent nature of solar energy limits a 24 hour operation and the effectiveness of solar thermal devices. Affordable and environmentally friendly materials for storing solar energy are currently in search. A natural convection solar cabinet dryer coupled with thermal energy storage bed (gravels) is modeled and simulated for space heating application (tomatoes drying) using TRNSYS 16 software. Performance of the solar thermal system (solar cabinet dryer) with a thermal storage bed will serve as a guide in developing a gravel-pit (GP) and or water-gravel pit storage system (WGPS) on a medium to large scale to facilitate solar thermal storage of heat for space and water heating applications in homes, health care and educational facilities. Thermal storage volume and thickness of gravel bed were determined and an optimized solar collector area obtained using TRNSYS 16 software for drying $6 \mathrm{~kg}$ of tomatoes slices. A computer program was written to predict the product drying temperature, mass of moisture removed, moisture content and drying rate at two different trays including solar collector efficiency, heat storage bed temperature profile using meteorological data input of dryer location, gravel properties, solar collector parameters and solar cabinet dryer chamber variables. The month of August was used as the design month bearing in mind that it has the least solar radiation in Bauchi and thus, predicted the least drying performance while, the month of March with the most solar radiation predicted the optimum drying performance. The maximum predicted gravel bed temperatures were 44 and $59.3^{\circ} \mathrm{C}$ for the months of August and March respectively. Predicted performance of the solar cabinet dryer was compared to a similar cabinet dryer without thermal storage bed. Predicted maximum product drying temperatures of 48 and $69^{\circ} \mathrm{C}$ were obtained for solar cabinet dryer with thermal storage bed as against 46 and $66^{\circ} \mathrm{C}$ for solar cabinet dryer without thermal storage bed in the month of August and March corresponding to solar intensity value of 575.4 and $1049.2 \mathrm{~W} / \mathrm{m}^{2}$ respectively. To attain $4.5 \%$ moisture content for $3 \mathrm{~kg}$ of tomatoes slices placed on each tray containing $94 \%$ of moisture, requires 37 (20 hours of sunshine and 7 hours of supplementary heat stored) and 53 (26 hours of sunshine and 6 hours of supplementary heat stored) hours of drying for solar cabinet dryer with thermal storage bed and, 52 (25 hours of sunshine) and 75 (34 hours of sunshine) hours under same weather condition for similar solar cabinet dryer without thermal storage bed for the month of March and August respectively. The average moisture extraction rate is 0.0759 and $0.0531 \mathrm{~kg}$ per hour in the month of March for solar cabinet dryer with and without thermal storage bed and, 0.0540 and $0.0374 \mathrm{~kg}$ per hour the month of August respectively. Predicted maximum solar collector efficiency for cabinet dryer with thermal storage bed is 50.12 and $43.85 \%$ for the month of March and August whereas, it was 45.83 and $37.66 \%$ for cabinet dryer without thermal storage bed respectively. The performance prediction of the solar cabinet dryer with thermal storage bed indicates clearly good potential for storing solar thermal heat collected during the day and effectively utilizing the stored heat during off-sunshine hours for heating applications. It is recommended that a gravel-pit (GP) and or water-gravel pit storage system (WGPS) should be developed and adequately studied for a range of operating parameters based on temperature distribution, thermal energy stored, available energy stored in the bed, energy consumption by blower (for active bed), and thermal efficiency of the collector to give clear guidelines for using the gravels for large scale solar thermal energy storage for space and water heating applications.
\end{abstract}

Index Terms: Transient Simulation, Solar Dryer, Thermal Bed, Insolation. 


\section{Introduction}

Drying is a simple process of moisture removal from an agricultural product in order to attain the desired moisture content and can be achieved through several methods such as open-sun drying, solar drying and mechanized drying. Solar drying is an energy intensive operation and depends on climatic conditions (humidity, wind speed, solar radiation, cloud cover, etc.) and drying materials’ properties (chemical composition, physical structure, size, shape, etc.) (Garg and Prakash, 2010). The removal of moisture prevents the growth and reproduction of microorganisms that causes decay, reduces the product weight and volume as well as the transportation cost. Solar dryers can be constructed from locally available materials and are useful in areas where fuel or electricity is expensive, land for sun drying is insufficient or expensive, sunshine is plentiful but the air humidity is high (Fellows, 1997). Besides, solar drying offers reduction to environmental risk compared to the mechanized drying method. Different types of solar dryers with varying sizes and designs have been developed and tested with some degree of efficiency. Studies have shown that solar dryers with auxiliary heating sources such as biomass back-up or thermal energy storage (sensible heat storage or latent heat storage) have better drying performances in terms of speed and quality of dried product. Nigeria is 14th largest producer of tomatoes in the world and second in Africa with over 1.8 million metric tons of annual production valued at 63 billion naira with an annual demand of 2.3 million metric tons valued at 80.5 billion naira. However, more than $45 \%$ of the crop produced in the country valued at 28.35 billion naira is lost after harvest due to inadequate processing and storage facilities, poor transportation network etc impacting negatively on food security and farmers' income. The challenge had led to the importation of tomato paste valued at over 360 million dollars in the country (CBN Annual report, 2017). The intermittent nature of solar radiation energy has made practically impossible to achieve 24 hours and all season's operation of solar thermal and photovoltaic devices. For solar thermal systems, it is practical impossible to in keeping systems temperature above the ambient except alternative energy sources are made available. The use of electric power is limited due to cost implication and negative environmental impact. The burning of agricultural waste such as biomass is tedious and has its environmental side effect. For solar thermal system such as a solar dryers, phase change materials (chemical energy storage), and the use of sensible heat storage materials such as bricks, pebbles, gravels, iron scraps are often used. The cost implication of the former also limits their usage while, the latter is advantageous for simplicity in design, low cost, stability under thermal cycling, good compatibility with storage containers, availability, non toxic among others. However, adequate knowledge of their thermal heat storage and transfer characteristics is essential is essential. To facilitate all day drying operation, keep drying chamber temperature above ambient, prevent moisture re-absorption and product deterioration during solar radiation off peak periods, a heat supplementary unit is need (Gutti et al., 2012; Shalaby, 2012). Beside solar drying operation of crops which is significant in the wet season when the clearness index is poor, the need to keep homes, educational and health facilities temperatures habitable during the cold season of harmattan. The research seek to model and simulate the performance of an indirect solar cabinet dryer with a thermal heat storage bed which could facilitates heat storage and retrieval for use during solar radiation off peak periods with specific objectives of determining: the product drying temperature of the system at two different trays; (ii). the temperature profile of the gravel heat storage bed; (iii). the rate of moisture removal; and (iv). the collector efficiency using TRNSYS software package. Quite a lot of research works have been carried out and validated using TRNSYS simulation program and other software packages. In a reported by Shariah and Shalabi (1997) in which they studied optimization of design parameters for a thermosyphon solar water heater for two regions of Amman and Aqaba in Jordan using TRNSYS simulation program indicate that the solar fraction could be improved by $10 \pm 25 \%$ when each studied parameter is chosen properly. It was also found that the solar fraction of the system installed in Aqaba, a hot climate region was less sensitive to some parameters than the solar fraction of a similar system installed in Amman, a mild climate region. Sebaii et al., (2010) developed a transient mathematical model based on an analytical solution of the energy balance equations for a single pass flat plate solar air heater. The model predicted the collector performance with good degree of accuracy. The system thermal performance was investigated for various black painted and selectively coated absorbers plates, and found that using Ni-Sn as a selective coating material achieved the best performance. Joshua et al., (2019) reported the work of Ayompe et al., (2011) where they utilize TRNSYS software for the performance evaluation and other parameter calculations for a forced flow in a flat plate and evacuated tube collector in Dublin. The validated result using experimental data for the systems indicated that the model predicted the collector outlet fluid temperature with percentage mean absolute error (PMAE) of $16.9 \%$ and $18.4 \%$ for the flat plate collector and evacuated tube collector systems respectively while, it was $14.1 \%$ and $6.9 \%$ and $16.9 \%$ and $7.6 \%$ for heat collected and delivered to the load respectively. The developed model underestimated the collector outlet fluid temperature by $-9.6 \%$ and overestimated the heat collected and heat delivered to load by $7.6 \%$ and $6.9 \%$ for the flat plate collector system. The TRNSYS model overestimated all three parameters by $13.7 \%, 12.4 \%$ and $7.6 \%$ for the evacuated tube collector system. Johnson et al., (2014) conducted a conceptual design and simulation of a 120 litres capacity solar domestic hot water thermosyphon system for Zaria-Nigeria. The design method employed is the simulation based method, where detailed mathematical models representing the design procedure of each component and whole system design is coded into a computer program using MATLAB programming language to calculate collector design parameters and system characteristics. The performance of the simulation base on optimal design parameters using TRNSYS 16 software reveal that the storage tank water temperature varies between 59 to $82^{\circ} \mathrm{C}$ at the end of each day for all year round for the location. This implies that a very significant fraction of the system load of a monthly average daily hot water demand of $0.1 \mathrm{~m} 3$ set at 
$90^{\circ} \mathrm{C}$ is made by the solar water heater indicating potentials in reduction of family utility bill for heating water. Johnson et al., (2015) predicted the long term performance of an active solar water heating system for domestic hot water application under the weather condition of Zaria-Nigeria using TRNSYS 16 software. The simulated system consists of a flat plate solar collector, with a total surface area of $2.2 \mathrm{~m} 2$, tilted at $12^{\circ}$ from horizontal, a thermally insulated vertical storage tank of 100 litres capacity, interconnecting piping and a solar pump. The result of the simulation reveals that the system is capable of meeting a daily domestic hot water load of 100 litres at a minimum temperature $61^{\circ} \mathrm{C}$ at the end of the day (5: $00 \mathrm{pm}$ ) for most part of the year except in the month of July where the tank temperature dropped to temperature below $34^{\circ} \mathrm{C}$ at the end of the day. Harikrishnan and Richu Zachariah (2016) presented a computational analysis to investigate the performance of a mixed mode solar dryer with thermal energy storage. The dryer incorporates a flat plate solar collector, a greenhouse, packed bed phase change energy storage and drying plenum with crop trays. Simulations using TRNSYS were done for the components for analyzing their heat gain and temperature. They developed a model for theoretical analyses of a flat plate using the Hottel-Whillier steady-state equations. TRNSYS software was used to simulate the system with air as the working fluid for useful gain of solar air heater, and variation in ambient and outlet temperature for the month of July. The simulation study shows that the solar dryer can effectively be use for fast drying purposes. Gideon (2016) predicted the long term performance of an active solar flat plate collector water heating system for providing hot water for a range of temperatures (for laundry; for post natal and for sterilization) at the Abubakar Tafawa Balewa University Medical Centre Bauchi-Nigeria using TRNSYS 16 software. The solar radiations and weather data were used as input into the design equations coded using MATLAB programming language to determine the system characteristics and components sizes. The simulation system consisted of a flat solar collector of adopted surface areas: $2.30 \mathrm{~m} 2,1.15 \mathrm{~m} 2$ and $2.1 \mathrm{~m} 2$ and a vertical storage tanks of volumes $0.15 \mathrm{~m} 3,0.113 \mathrm{~m} 3$ and $0.088 \mathrm{~m} 3$ for laundry, post natal and sterilization applications respectively, with interconnecting piping and a solar D.C. pumps. The monthly average hourly performance of the system for the recommended average days for the months was numerically simulated based on Typical Meteorological Year (TMY) weather data for the said location. The results of the simulation show the system capability of meeting a daily hot water requirement of $540 \mathrm{C}, 43^{\circ} \mathrm{C}$ and $60^{\circ} \mathrm{C}$ for the laundry, post natal and sterilization applications respectively. The statistical indicated a good agreement between the predicated and experimental result.

The schematic diagram of the solar cabinet dryer is shown in Fig. 1. The system is made up of two main compartments namely: the solar energy collector/heat storage unit and the drying chamber. The system's absorber plate is made of aluminum for maximum solar radiation absorption and a single glass cover of low emissivity, while the drying chamber consists of two trays. The main purpose of the gravel heat storage bed is to improve the match between the collected energy and the load, minimize fluctuation in drying air temperatures of the system during solar radiation off peak periods.

\section{Materials and Methods}

\subsection{Materials}

The solar cabinet dryer is designed for drying agricultural product that need moderate temperature rise (not more than $70^{\circ} \mathrm{C}$ ) above the ambient temperature to avoid lost in nutrient during drying (Richard, 2013). Appropriate dimensions of collector depth, collector width, diameter of the hole and pitch for the collector air flow inlet were selected using the TRNSYS 16 software to keep the temperature not to exceed $70^{\circ} \mathrm{C}$. Thermal properties of Ojano gravels located in Otukpo local government area of Benue state which served as thermal heat storage media is show in Table 1. The KD2 Thermal Pro instrument was used for the thermal properties measurement of Ojano gravel. The instrument works on the principle of transient line heat source method meant for thermal properties determination of soils and gravels. It is calibrated with a multi sensors usage (single needle sensors and dual sensors). These properties (better absorptivity and storability including slower rate of heat release) make Ojano gravel, the most preferred gravel among others for the solar dryer system (will aid prolong drying). Also, preliminary studies using TRNSYS 16 software shows Ojano gravel as the most advantageous for gradual release of heat thus aiding prolong drying after sunset hours. Aluminium plate material is selected for the absorber plate over copper, silver and other materials due to its light weight, lower cost, ease of fabrication and energy effectiveness in use of the material (Lotfalian et al., 2010). 


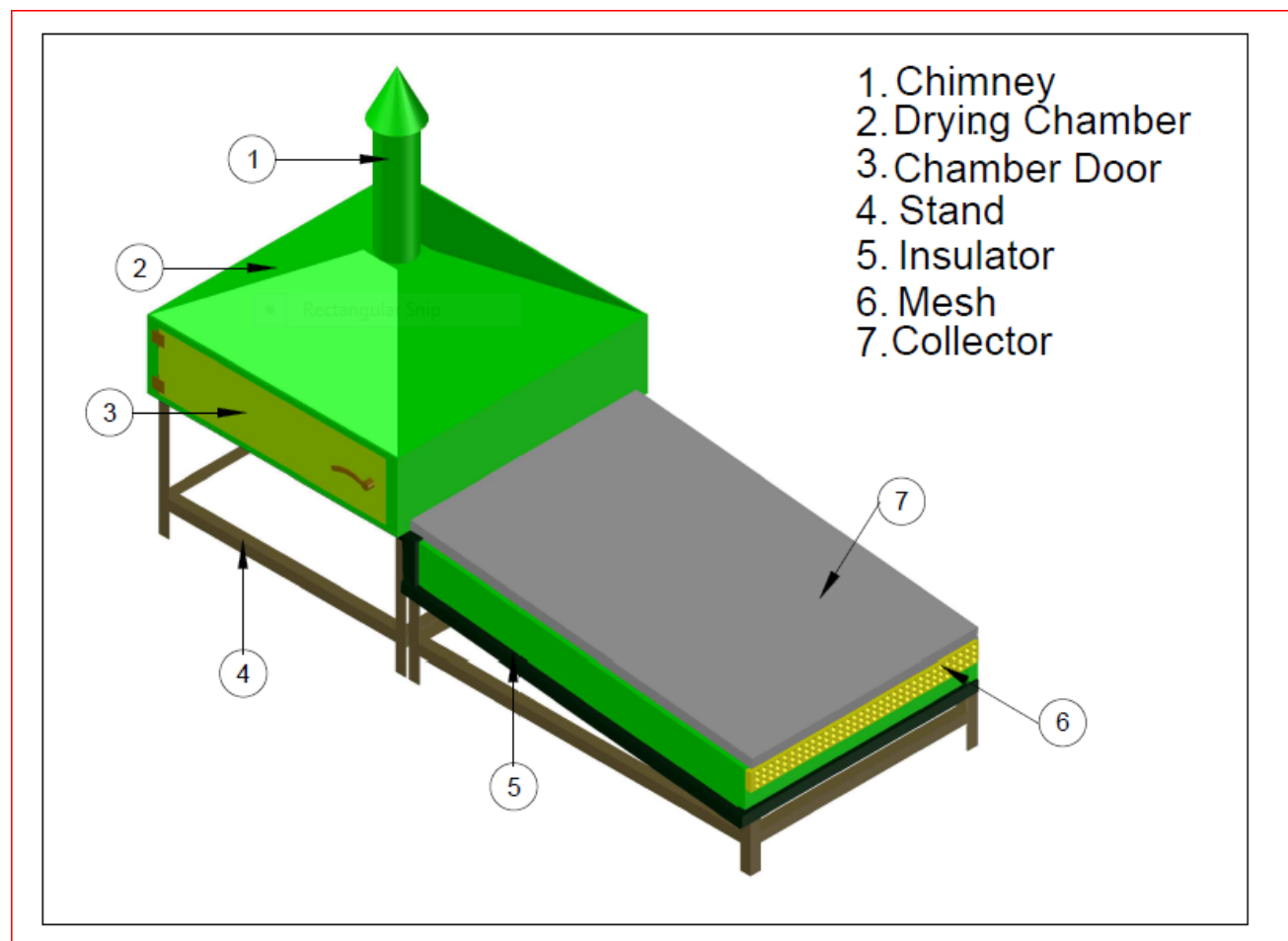

Fig. 1: The solar cabinet dryer with inclined single air-pass collector integrated with gravel heat storage bed

Table 1. Thermo-physical properties of Ojano gravels of Benue state

\begin{tabular}{|c|c|c|c|c|}
\hline $\begin{array}{c}\text { Density } \\
\left(\mathrm{kg} / \mathrm{m}^{3}\right)\end{array}$ & $\begin{array}{c}\text { Specific heat capacity } \\
(\mathrm{J} / \mathrm{kgK}) .\end{array}$ & $\begin{array}{c}\text { Thermal conductivity } \\
(\mathrm{W} / \mathrm{mK})\end{array}$ & $\begin{array}{c}\text { Thermal diffusivity } \\
\left(\mathrm{m}^{2} / \mathrm{s}\right) \\
(\times \mathrm{E}-06)\end{array}$ & $\begin{array}{c}\text { Thermal effusivity (Thermal admittance) } \\
\left(\mathrm{W} / \mathrm{m}^{2} \mathrm{~K}\right)\end{array}$ \\
\hline 3370 & 1132.09 & 4.00 & 1.0484 & 3906.48 \\
\hline
\end{tabular}

\subsection{Methods}

\subsubsection{Design considerations and assumptions}

The design conditions and other assumptions are summarized in Table 2.

Table 2. Design Specifications and Assumptions

\begin{tabular}{ll}
\hline Parameter & Condition \\
\hline Material & Tomatoes \\
Initial moisture content, \% & 94 \\
Final moisture content,\% & 4.5 \\
Average ambient temperature, ${ }^{\circ} \mathrm{C}$ & 25 \\
Density of air at ambient, $\mathrm{kg} / \mathrm{m}^{3}$ & 1.21 \\
Maximum allowable temperature, ${ }^{\circ} \mathrm{C}$ & 70 \\
Drying period & All year \\
Dryer capacity per batch, $\mathrm{kg}$ & 6 \\
Number of drying trays & 2 \\
Drying capacity per tray, kg & 3 \\
Thermal conductivity of saw dust, $\mathrm{W} / \mathrm{mK}$ & 0.08 \\
Bottom insulation thickness, $\mathrm{m}$ & 0.05 \\
Side thickness insulation, $\mathrm{m}$ & 0.025 \\
Temperature elevation of gravel bed, ${ }^{\circ} \mathrm{C}$ & 30 \\
Efficiency of gravel bed heat storage, $\%$ & 30 \\
\hline
\end{tabular}

\subsubsection{Design Calculations}

From the design conditions, assumptions and relationships, the values of the design parameters were calculated and given in Table 2.

\subsubsection{Amount of moisture removed from the product, $\mathrm{kg}\left(\mathrm{m}_{w}\right)$}

The amount of moisture to be removed from the product, $m_{w}(\mathrm{~kg})$ was calculated using the following equation as reported by Gutti et al. (2012):

$$
m_{w}=m_{p}\left(\frac{m_{i}-m_{f}}{100-m_{f}}\right)
$$


2.2.2.2 Quantity of heat energy required for evaporating moisture from the product, $Q$

The quantity of heat energy required to evaporate moisture from the product to be dried is given by (Gutti et al., 2012):

$$
Q=m_{w} \times h_{f g}
$$

The latent heat of vapourization of water was estimated using the following relation (Youcef-Ali et al., 2001):

$$
h_{f g}=4186\left(597-0.56 T_{p r}\right)
$$

2.2.2.3 Volume of gravel heat storage material, $m 3$

The volume of the heat storage material, $V_{s}$ is calculated from the total energy required by the storage material to heat up the flowing air (Atkilt, 2013).

$$
m_{r} \times C_{p r \times} \Delta T=\frac{m_{a} \times C_{p a} \times \Delta T}{n_{s}}
$$

where

$$
m_{r}=\rho_{r} \times V_{s}
$$

and

$$
\begin{gathered}
\rho_{r} \times V_{s} \times C_{p r} \times \Delta T=\frac{m_{a} \times C_{p a} \times \Delta T}{n_{s}} \\
m_{a} \times C_{p a} \times \Delta T=m_{w} \times h_{f g}=Q_{T} \\
V_{s}=\frac{m_{a} \times C_{p a} \times \Delta T}{n_{s} \times C_{p r} \times \Delta T \times \rho_{r}}
\end{gathered}
$$

The volume of the storage material, $V_{s}$ is then calculated from equation 8.

Since most of the moisture of the crop would be evaporated during the day time directly by solar energy, the thickness of the storage bed will be taken as $40 \%$ of the calculated as recommended by Atkilt (2013).

2.2.2.5 Thickness of gravel heat storage material, $R_{t}$

The thickness of the gravel bed heat storage material, $R_{t}$ is determined from the expression relating the volume of the gravel and the solar collector area (Atkilt, 2013).

$$
R_{t}=\frac{V_{s}}{A_{c}}
$$

2.2.2.6 Volumetric and mass air-flow rates

The volumetric flow rate of air is given as reported by (Onigbogi et al., 2012):

$$
V_{a}=A \times v_{a}
$$

The mass air-flow rate was obtained as:

$$
m_{a}=\rho_{a} \times V_{a}
$$

2.2.2.7 Chimney height and diameter

The chimney surface area is calculated by dividing the volumetric air flow rate by the wind-speed (Onigbogi et al., 2012).

$$
A_{v}=\frac{v_{a}}{v_{a}}
$$

For a cylindrical chimney of $0.75 \mathrm{~m}$ height (Kamble and Dombale, 2016), the radius of the chimney is expressed as:

$$
r=\frac{A_{v}}{2 \pi r h}
$$


Table 3. Specifications of the Solar Cabinet Dryer from Calculations

\begin{tabular}{|c|c|}
\hline Parameter & Value \\
\hline Bottom insulation thickness, $\mathrm{m}$ & 0.050 \\
\hline Side insulation thickness, $\mathrm{m}$ & 0.025 \\
\hline Volume of gravel heat storage material bed, $\mathrm{m}^{3}$ & 0.157 \\
\hline Length of gravel heat storage material bed, $\mathrm{m}$ & 1.500 \\
\hline Thickness of gravel heat storage material bed, $\mathrm{m}$ & 0.100 \\
\hline Cross-sectional area of gravel heat storage material bed, $\mathrm{m}^{2}$ & 0.100 \\
\hline Height of drying chamber, m & 0.300 \\
\hline Volume of drying chamber, $\mathrm{m}^{3}$ & 0.300 \\
\hline Length of drying tray, $\mathrm{m}$ & 1.000 \\
\hline Width of drying tray, $\mathrm{m}$ & 1.000 \\
\hline Vertical distance between trays, $\mathrm{m}$ & 0.100 \\
\hline Clearance between solar collector exit air and first tray, $\mathrm{m}$ & 0.100 \\
\hline Clearance between second tray and chimney, $\mathrm{m}$ & 0.100 \\
\hline Height of chimney, m & 0.375 \\
\hline Diameter of chimney, $\mathrm{m}$ & 0.040 \\
\hline Optimized collector area, $\mathrm{m}^{2}$ & 1.500 \\
\hline
\end{tabular}

\subsection{Mathematical Modeling of the Solar Cabinet Dryer}

The equations for the heat transfer characteristics of the system are developed based on the law of conservation of energy. In this research work, TRNSYS 16 software is used to evaluate and predict the monthly performance of a two tray solar cabinet passive dryer under the climatic condition of Bauchi, latitude $10.3010^{\circ} \mathrm{N}, 9.8237^{\circ}$ E. The solar collector equations are built in TRNSYS 16. The sectional view of the solar cabinet dryer is shown in Figure 2 . The following are the assumptions:

1. Heat transfer coefficients for the system are constant along solar heater air passage

2. The heat storage bed has uniform bed porosity.

3. Transient state condition parameters

4. The mass flow rate is constant across the drying system.

5. The specific heat capacity of air is constant across the drying system.

6. The latent heat of vaporization of water is dependent on the drying air temperature across the trays.

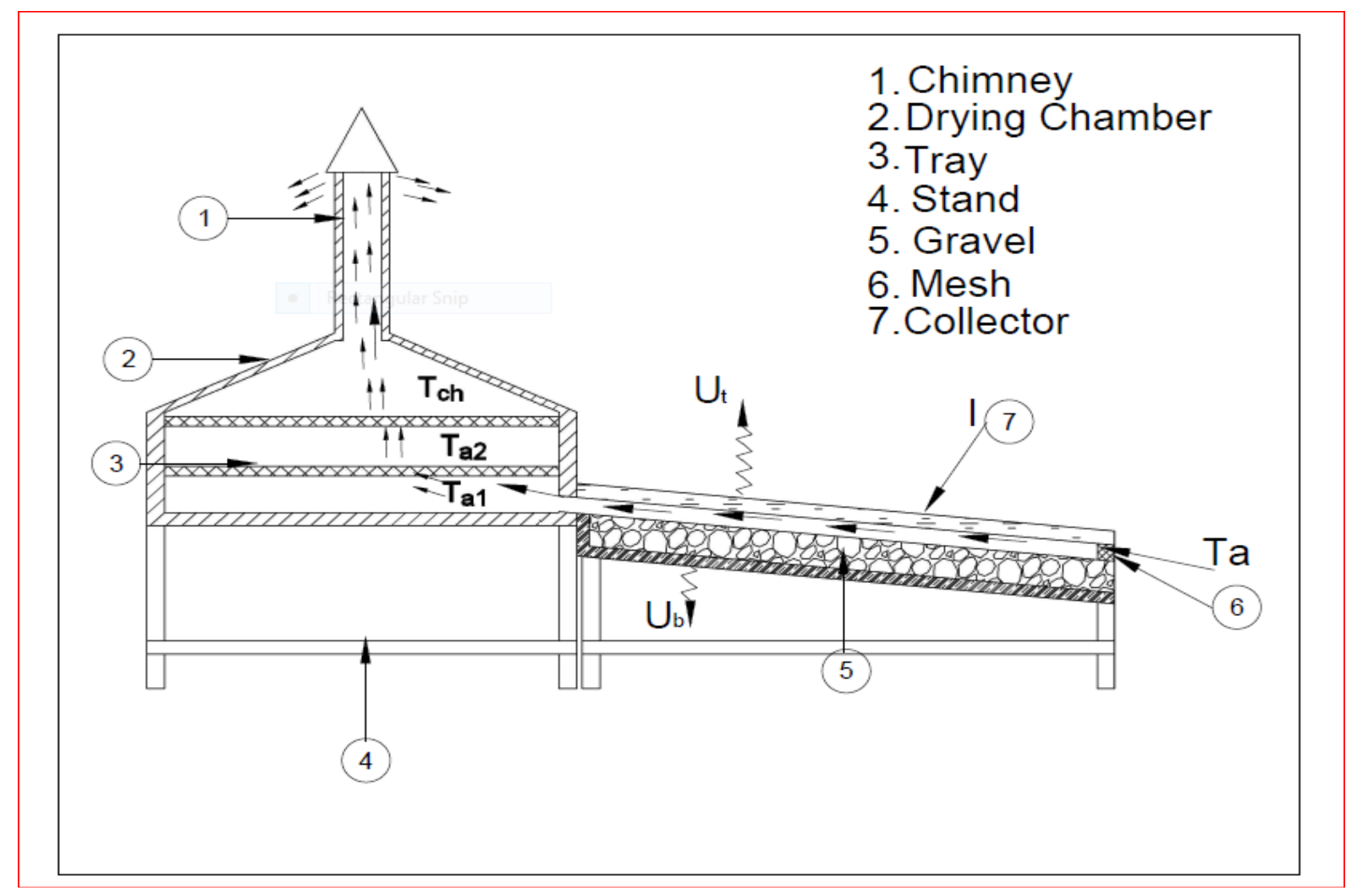

Fig. 2. Sectional view of the solar cabinet dryer with inclined single air-pass collector with thermal energy storage bed 


\subsubsection{Solar collector}

The proposed dynamic collector model is based on the well validated model for solar thermal collectors and general heat transfer. The model is based on the Hottel-Whillier Bliss equation for flat plate solar collectors (Harikrishnan and Richu Zachariah, 2016). The TRNSYS 16 simulation software has the inbuilt solar collector. The characteristics properties of the collector used are shown in Table 3:

Table 4. Solar Collector Parameters

\begin{tabular}{ll}
\hline Parameter & Value \\
\hline Glazing (Glass) & 1.5 \\
Refractive index of glass & 1 \\
Number of glazing & 10.23 \\
Latitude of Bauchi, degree & 4 \\
Thickness of glazing, mm & 0.2 \\
Reflective index of glazing & 0.88 \\
Emittance of glazing & 0.28 \\
Absorptance of glazing & 1.05 \\
Thermal conductivity of glazing, W/Mk & \\
Absorber plate (Aluminium) & 0.95 \\
Emittance & 0.9 \\
Absorptance & 0.05 \\
Thickness of absorber plate, $\mathrm{m}$ & 205 \\
Thermal conductivity of plate, W/mK & 900 \\
Specific heat capacity of absorber plate, J/kgK & \\
\hline
\end{tabular}

\subsubsection{Gravel bed temperature}

For inclined solar collector with inbuilt thermal energy storage bed, the bed temperature is given by equation 14 (TRNSYS 16, 2011):

$$
-A \rho_{r} C_{p r} \frac{\partial T}{\partial t}=m_{a} C_{p a} \frac{\partial T}{\partial t}+U P\left(T_{r}-T_{a}\right)
$$

2.3.3 Energy balance in the drying chamber

The solar air heater outlet temperature serves as the product drying temperature on tray $1, T_{a 1}$ while, $T_{a}$ is the solar air heater inlet temperature taken as the ambient temperature.

2.3.4 Product drying temperature on tray 1

$$
\begin{aligned}
& m_{a} C_{p a}\left(T_{a 1}-T_{a 2}\right)=m_{w 1} h_{f g 1} \\
& T_{a 2}=T_{a 1}-\frac{m_{w 1} h_{f g 1}}{m_{a} C_{p a}}
\end{aligned}
$$

2.3.5 Product drying temperature on tray 2

$$
\begin{aligned}
& m_{a} C_{p a}\left(T_{a 2}-T_{c h}\right)=m_{w 2} h_{f g 2} \\
& T_{c h}=T_{a 2}-\frac{m_{w 2} h_{f g 2}}{m_{a} C_{p a}}
\end{aligned}
$$

2.3.6 Product drying temperature on ith number of tray

$$
\begin{aligned}
& m_{a} C_{p a}\left(T_{i+1}-T_{i}\right)=m_{w i} h_{f g i} \\
& T_{i+1}=T_{i}-\frac{m_{w i} h_{f g i}}{m_{a} C_{p a}}
\end{aligned}
$$

where: $\mathrm{i}=1,2,3,4,5$ etc represents different layers of drying

\subsection{Mass balance in the drying chamber}

The density of air, humidity ratio, air flow rate, product thickness, product area and product density are given as $\rho_{a}$, $H_{a}, V_{a}, D_{c}, A_{p}$ and $\rho_{c}$ respectively. 
2.4.1 Mass balance on tray 1

$$
\rho_{\mathrm{a} 1} \mathrm{~V}_{\mathrm{a} 1} \frac{\mathrm{dH}_{1}}{\mathrm{dt}}=\left(\rho_{\mathrm{a} 1} \mathrm{H}_{\mathrm{a} 1} \mathrm{~V}_{\mathrm{a} 1}-\rho_{\mathrm{a} 1} \mathrm{H}_{\mathrm{a} 2} \mathrm{~V}_{\mathrm{a} 1}\right)+\mathrm{A}_{\mathrm{p} 1} \mathrm{D}_{\mathrm{c} 1} \rho_{\mathrm{c} 1} \frac{\mathrm{dM}_{\mathrm{c} 1}}{\mathrm{dt}}
$$

2.4.2 Mass balance on tray 2

$$
\rho_{\mathrm{a} 1} \mathrm{~V}_{\mathrm{a} 1} \frac{\mathrm{dH}_{2}}{\mathrm{dt}}=\left(\rho_{\mathrm{a} 1} \mathrm{H}_{\mathrm{a} 2} \mathrm{~V}_{\mathrm{a} 1}-\rho_{\mathrm{a} 1} \mathrm{H}_{\mathrm{ach}} \mathrm{V}_{\mathrm{a} 1}\right)+\mathrm{A}_{\mathrm{p} 2} \mathrm{D}_{\mathrm{c} 2} \rho_{\mathrm{c} 2} \frac{\mathrm{dM}_{\mathrm{c} 2}}{\mathrm{dt}}
$$

2.4.3 Mass balance on ith number of tray

$$
\rho_{\mathrm{a} 1} \mathrm{~V}_{\mathrm{a} 1} \frac{\mathrm{dH}}{\mathrm{dt}}=\left(\rho_{\mathrm{a} 1} \mathrm{H}_{\mathrm{ai}} \mathrm{V}_{\mathrm{a} 1}-\rho_{\mathrm{a} 1} \mathrm{H}_{\mathrm{ai}+1} \mathrm{~V}_{\mathrm{a} 1}\right)+\mathrm{A}_{\mathrm{pi}} \mathrm{D}_{\mathrm{ci}} \rho_{\mathrm{ci}} \frac{\mathrm{dM}_{\mathrm{ci}}}{\mathrm{dt}}
$$

2.5 Solar Dryer Performance Evaluation

\subsubsection{Solar collector efficiency}

This is computed from equation 38 given by Ahmed (2011).

$$
n_{c}=\frac{\rho v C_{p}\left(T_{a 1}-T_{a}\right)}{A_{c} I}
$$

2.5.2 Instantaneous moisture content

According to Atkilt (2013), the instantaneous moisture content is given as:

$$
\begin{gathered}
m_{r}=\frac{m_{f}-m_{e q}}{m_{i}-m_{e q}}=\exp ^{-k t} \\
m_{f}=\left(m_{i}-m_{e q}\right) \exp ^{-k t}+m_{e q} \\
k=139.3 \exp \left(\frac{-7676}{((1.8 T)+492)}\right)
\end{gathered}
$$

\subsubsection{Drying rate}

The drying rate, $D_{R}$, is determined from the mass of moisture removed and the drying time taken for the operation and is expressed as given in equation (28) given by Sengar et al., (2012):

$$
D_{R}=\frac{m_{w}}{t_{d}}
$$

2.5.4 Mass of moisture removed

Ahmed (2011) gave the mass of moisture removed, $M_{L}(\mathrm{~kg})$ as:

$$
M_{L}=\left(m_{i}-m_{f}\right)
$$

\subsection{System Performance Simulation}

Transient system simulation (TRNSYS) is a modular structure program appropriate for simulating the performance of systems as a function of passage of time when influencing system conditions turn to change such as weather. In essence, the variation in system components conditions with time. The identification of system components, formulation of relevant equations and their interconnectivity between them that describes the performance of the system is vital. The simulated solar cabinet dyer consists of the solar air heater (solar collector), heat storage bed beneath the collector and the drying chamber. A single glazing thermal solar collector model was developed using the system inbuilt collector model by assigning values to the collector parameter in order to determine the collector available useful energy for heating the ambient air with the available solar radiation. A thermal heat storage bed was also developed alongside the solar thermal collector to facilitate the storage of heat during the heating process. The weather file data for the location which contains all necessary information that could lead to the availability of solar radiation at any selected day and time was use. Basic heat transfer equations for the drying trays were derived based on deep bed model. According to Misra and Brooker (1980) and Gunasekaran and Thompson (1986), a deep bed model consists of a series of thin-layers in the drying system where each thin-layer modifies the air property and therefore, only the first thin layer receives air flow with constant air properties. This reduces the moisture content of the crop on the first layer faster than successive layers. TRNSYS components which represent each physical components of the model system are selected from the component library. These components are then connected in such a manner that represents the flow of information from one component of the system to another. Equations for collector useful energy, control of air flow rate at the collector inlet, gravel bed temperature, drying product temperature, mass of moisture removed, moisture content, drying rate, and collector efficiency are developed and coded in MATLAB programming landuage at the various selected TRNSYS components which represent each physical component of the physical model system. TRNSYS software was then used to study and optimized the drying chamber volume and vertical distance between trays. A computer program was written to forecast the collector outlet temperature, gravel bed temperature, mass of moisture removed, instantaneous moisture content, drying rate, collector efficiency and other engineering variables from the 
input of the meteorological data (Bauchi weather), parameters of collector and gravel bed heat storage, and drying chamber. The system was then simulated using TRNSYS 16 software based on the system design parameters and characteristics involved in the drying process. The climatic condition was based on typical metrological year (TMY) weather data for the location of Bauchi with the system characteristics as indicated in Tables 1,2 and 3 . The monthly average recommended days by Klein et al., (1996) for the months were used. The schematic model used for the simulation is shown in Figure 3 while the simulated results are given in Figures 4 to 21 . Figure 3 is the TRNSYS simulation diagram the arrangement of the system main components (solar collector, gravel bed thermal storage bed, drying chamber). The weather data file supplies the solar collector the necessary information for elevating the solar collector useful energy. The solar collector is integrated with a thermal storage bed which stores part the useful energy while, the remaining enters the drying chamber as tray one product drying air temperature (Fig. 3). The drying chamber houses two drying trays positioned vertically and then receive tray one exit air for drying operation on tray two before existing the drying chamber through the chimney.

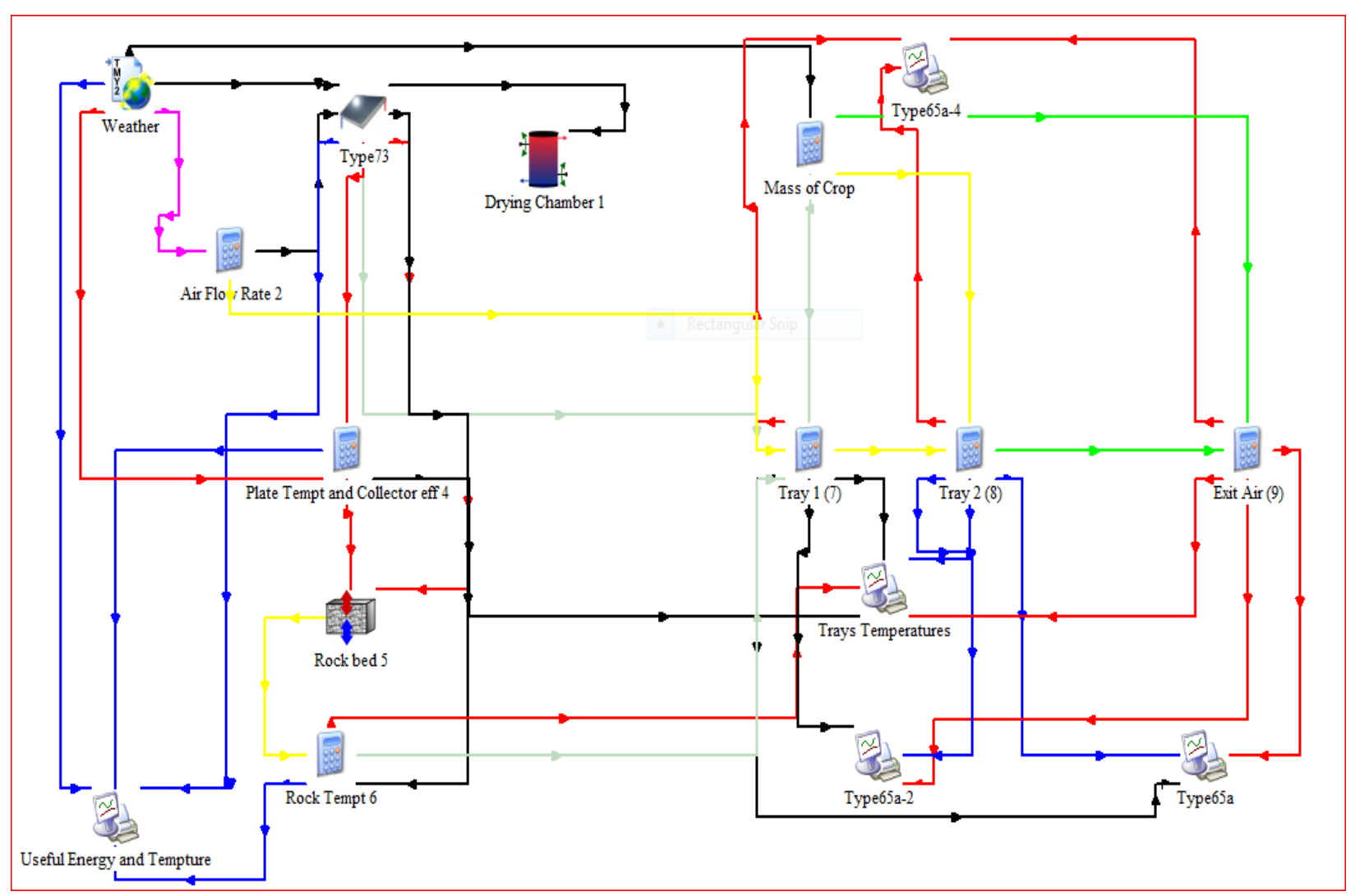

Fig. 3. TRNSYS model diagram for solar cabinet dryer with air as heat transfer fluid

\section{Results and Discussion}

\subsection{Solar Intensity, Ambient, Drying Product and Gravel Bed Temperatures}

The variation in the predicted solar intensity, ambient, drying product and gravel bed temperatures for the month of August and March are shown in Figures 4 to 7 for cases of dryer with heat storage and without storage. The results revealed that the performance of the solar cabinet dryer is dependent on the intensity of the solar radiation, ambient temperature and the stored heat in the gravel bed. The predicted gravel bed temperature increases from 8:00am steadily and reaches an average maximum of 44.9 and $59.3^{\circ} \mathrm{C}$ between the hours of 1:00 and 2:00pm at a corresponding solar intensity of 575.4 and $1049.2 \mathrm{~W} / \mathrm{m} 2$ for the months of August and March respectively (Fig. 4 and 6). The solar cabinet dryer maximum product drying temperatures were found to be 47.7 and $68.8^{\circ} \mathrm{C}$ for the months of August and March with heat storage medium and, 45.9 and $65.6^{\circ} \mathrm{C}$ for dryer without heat storage bed respectively (Fig. 4-7). The slightly higher temperature exhibited by dryer incorporated with a heat storage bed is due to its ability to retain constant heat with the introduction of the gravel bed beneath the collector absorber plate thus minimizing quick heat lost from the collector. From the model prediction, product dried using solar cabinet dryer with heat storage system will reach equilibrium moisture content faster due to prolong drying using supplementary heat stored in the gravel bed. The prolong drying exhibited in the drying chamber after sunset is attributed to the gradual release of heat from the thermal storage bed under natural convection in-addition to proper match of the air flow rate in the solar collector. This work agrees with that of Benjamin and Muhammad (2017) who achieved drying chamber temperature range of 29 to $56.5^{\circ} \mathrm{C}$, while the heat storage bed temperature range was from 31 to $57.8^{\circ} \mathrm{C}$ at the uppermost part of the heat bed in the month of February for same location. 


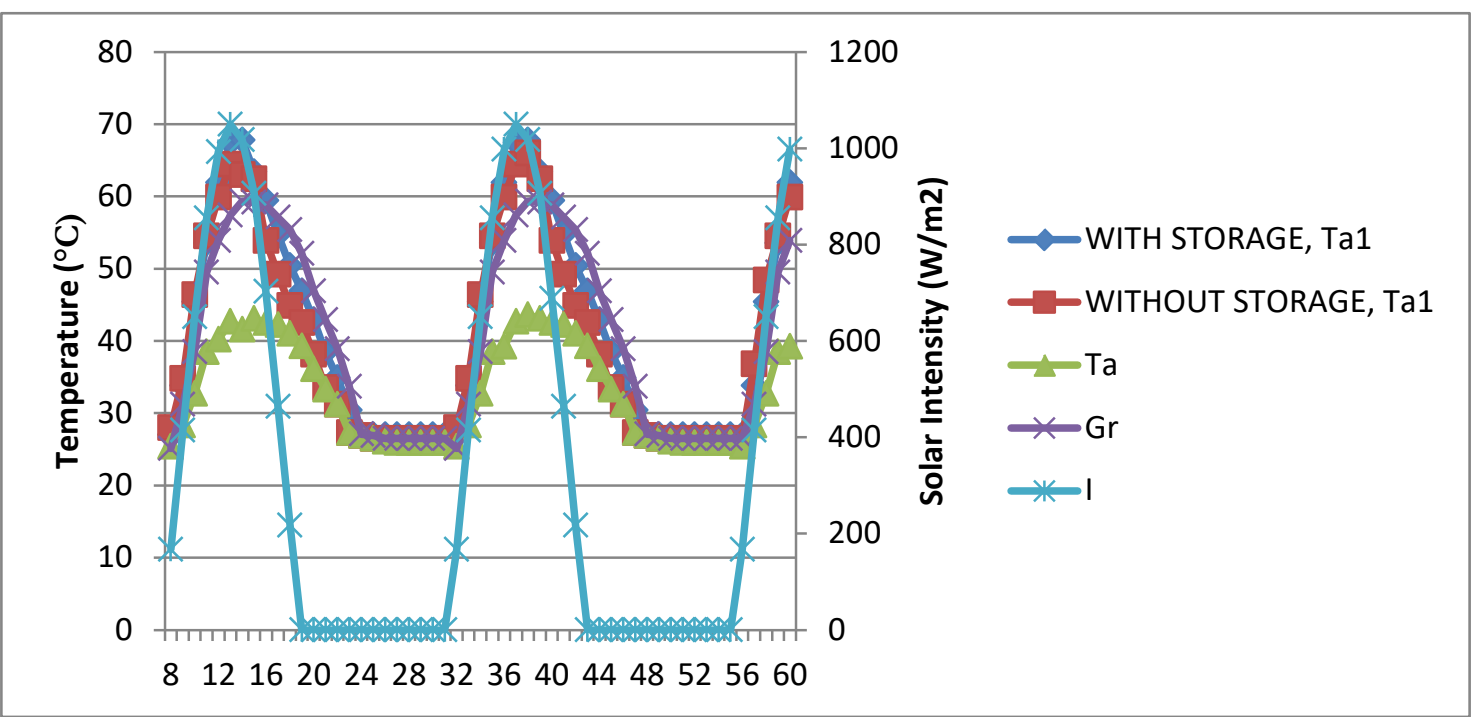

Fig. 4. Variation of predicted solar intensity, product drying, ambient and gravel bed temperatures against drying time on the 16, 17 and 18 th of March for solar cabinet dryer with and without heat storage bed for tray 1

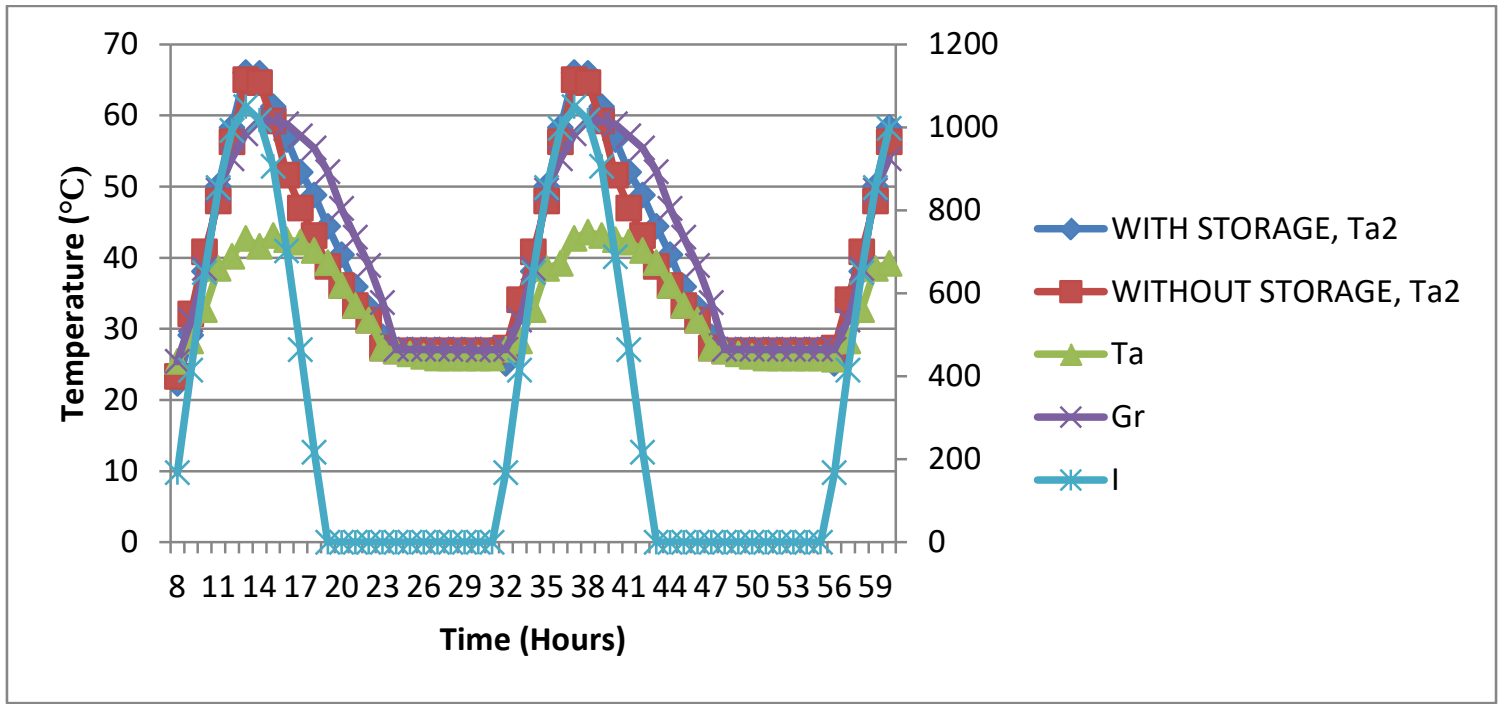

Fig. 5. Variation of predicted solar intensity, product drying, ambient and gravel bed temperatures against drying time on the 16, 17 and 18th of March for solar cabinet dryer with and without heat storage bed for tray 2

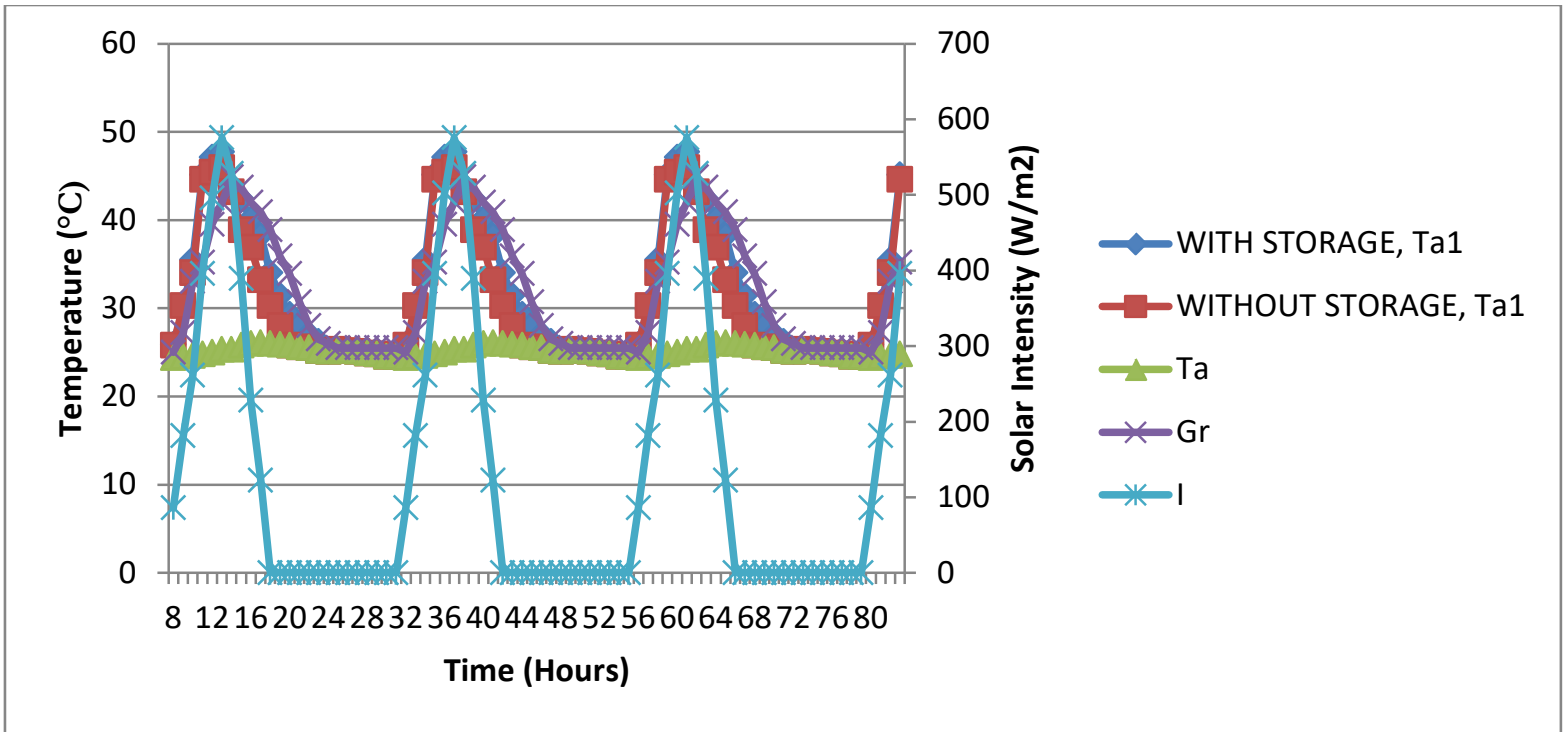

Fig. 6. Variation of predicted solar intensity, product drying, ambient and gravel bed temperatures against drying time on the 16, 17, 18 and 19th of August for solar cabinet dryer with and without heat storage bed for tray 1 


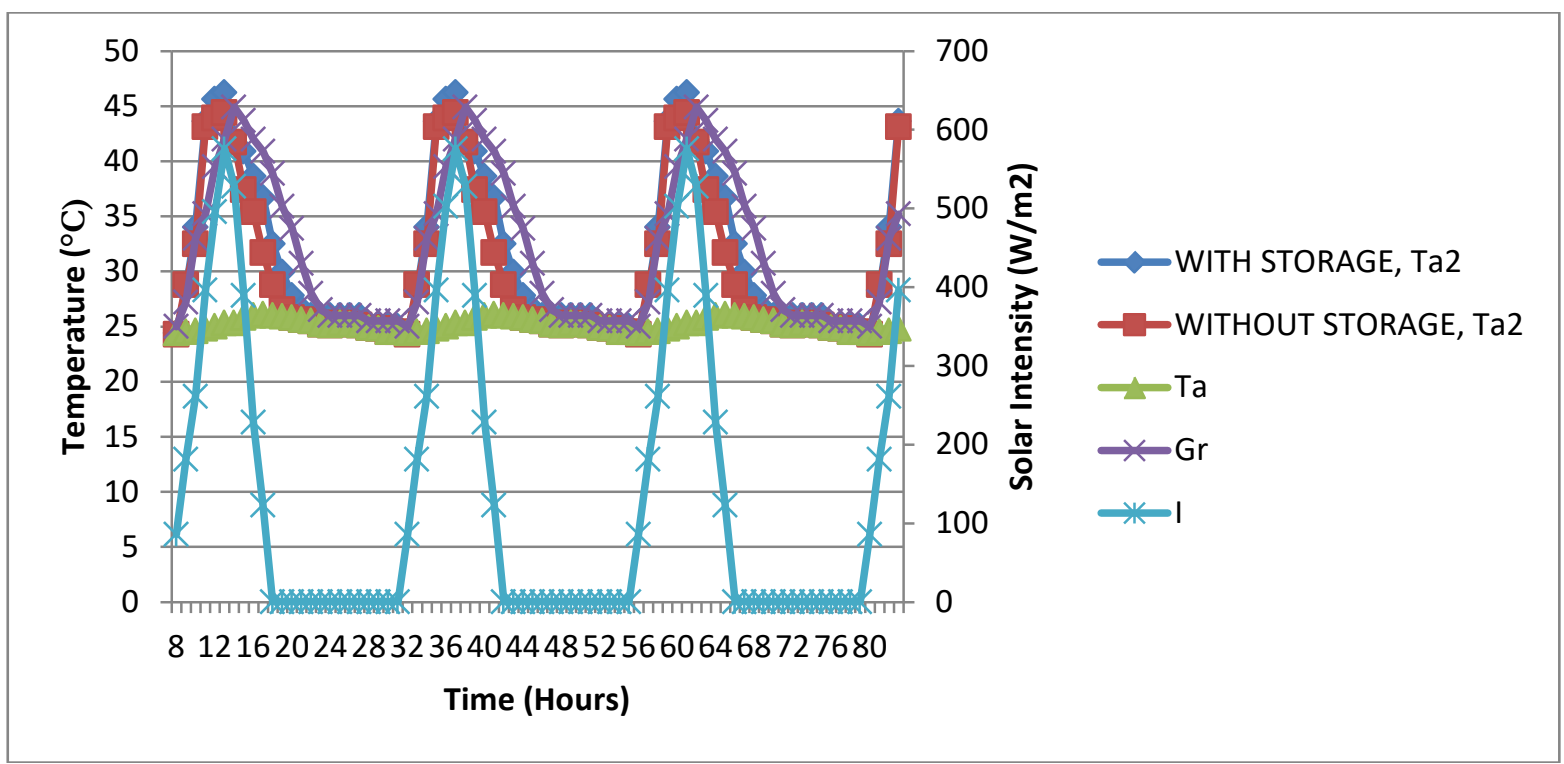

Fig. 7. Variation of predicted solar intensity, product drying, ambient and gravel bed temperatures against drying time on the 16, 17, 18 and 19 th of August for solar cabinet dryer with and without heat storage bed for tray 2

\subsection{Mass of Moisture Removed}

Fig. 8 to 11 depict the mass of moisture removed from tomatoes as a function of the drying time for tray 1 and 2 in the months of March and August for solar cabinet dryer with and without a heat storage bed. For each drying tray placed with $3 \mathrm{~kg}$ of product and $94 \%$ moisture content, $2.81 \mathrm{~kg}$ moisture is required to be removed to attend a safe storage moisture content of $4.5 \%$ (equilibrium moisture content). To achieve $2.81 \mathrm{~kg}$ moisture removal using solar cabinet dryer with thermal storage medium, 37 hours of drying (20 hours of sunshine and 7 hours of supplementary heat stored), and 53 hours of drying (26 hours of sunshine and 6 hours of supplementary heat stored) for the months of March and August respectively were recorded whilst for solar cabinet dryer without heat storage, 52 hours (25 hours of sunshine), and 75 (34 hours of sunshine) were required for the drying operation (Figures 8-11). Thus, the used of supplementary heat for solar cabinet dryer with thermal storage bed achieved a significant reduction in the total drying time compared to the dryer without the heat medium. This is in support of the study conducted by Shalaby (2012) where supplementary heat (sand) stored beneath the solar collector absorber plate achieved a reduction of 3 hours in drying time for $1 \mathrm{~kg}$ of grape in a forced convection solar cabinet dryer.

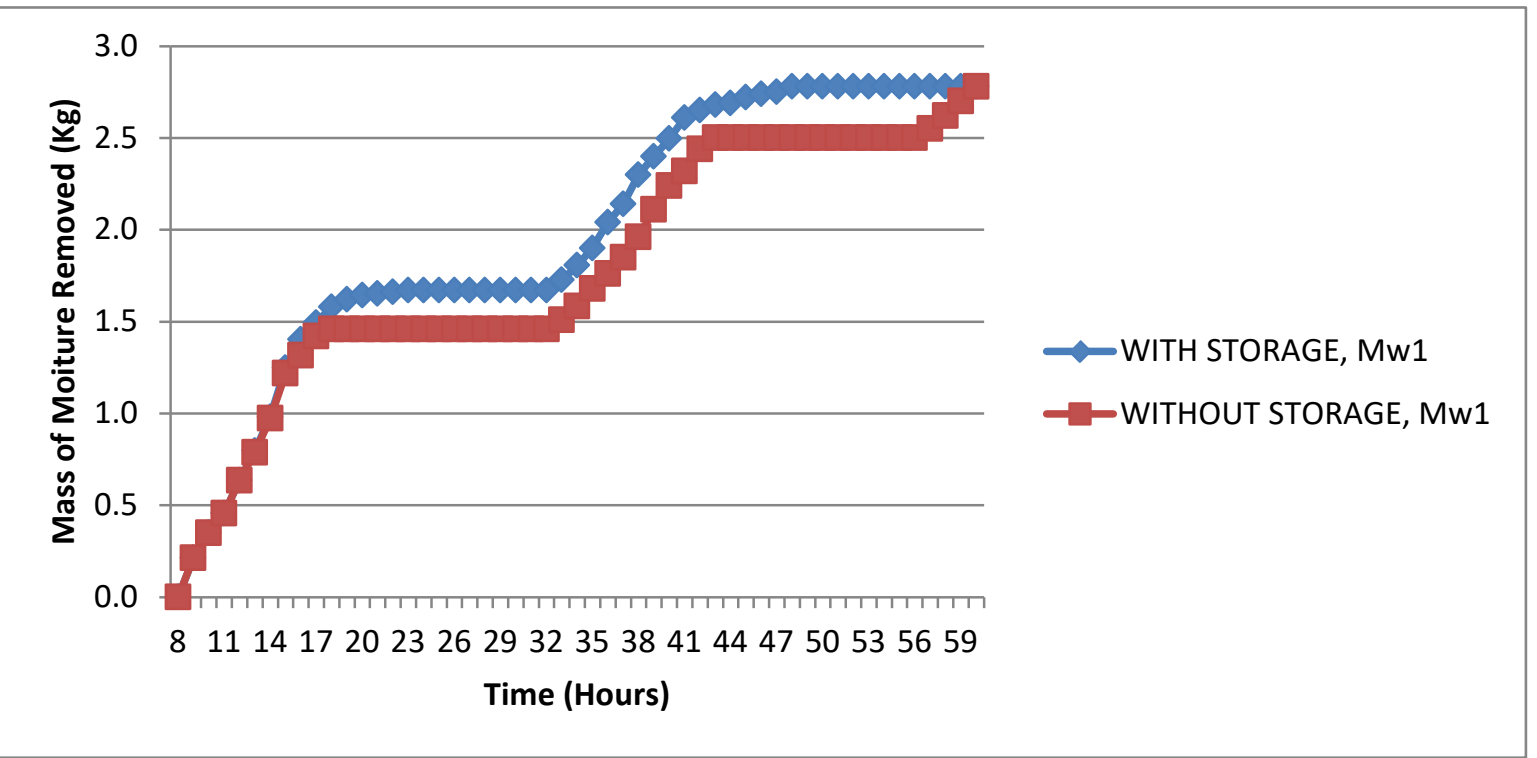

Fig. 8. Variation of predicted moisture removed against drying time on the 16, 17 and 18th of March for solar cabinet dryer with and without heat storage bed for tray 1 


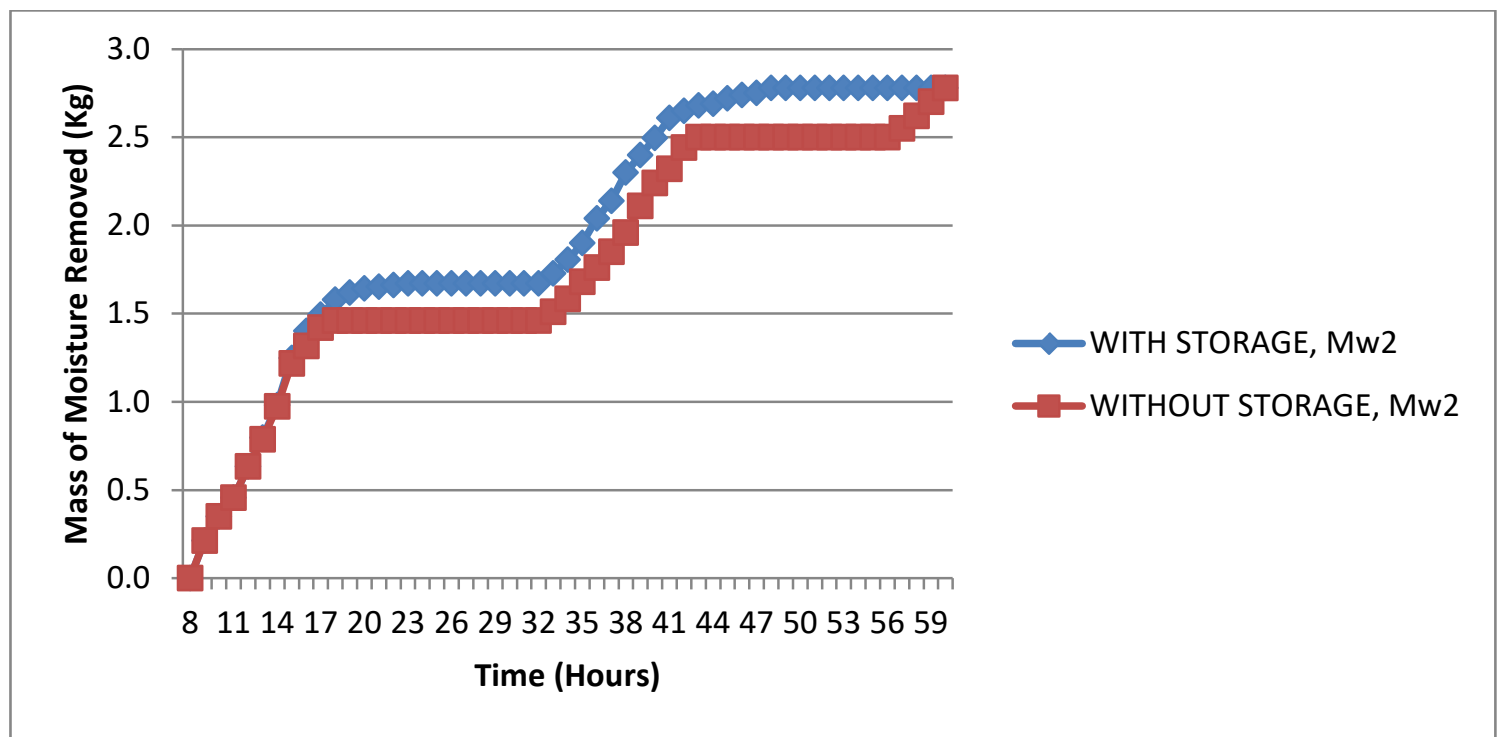

Fig. 9. Variation of predicted moisture removed against drying time on the 16, 17 and 18th of March for solar cabinet dryer with and without heat storage bed for tray 2

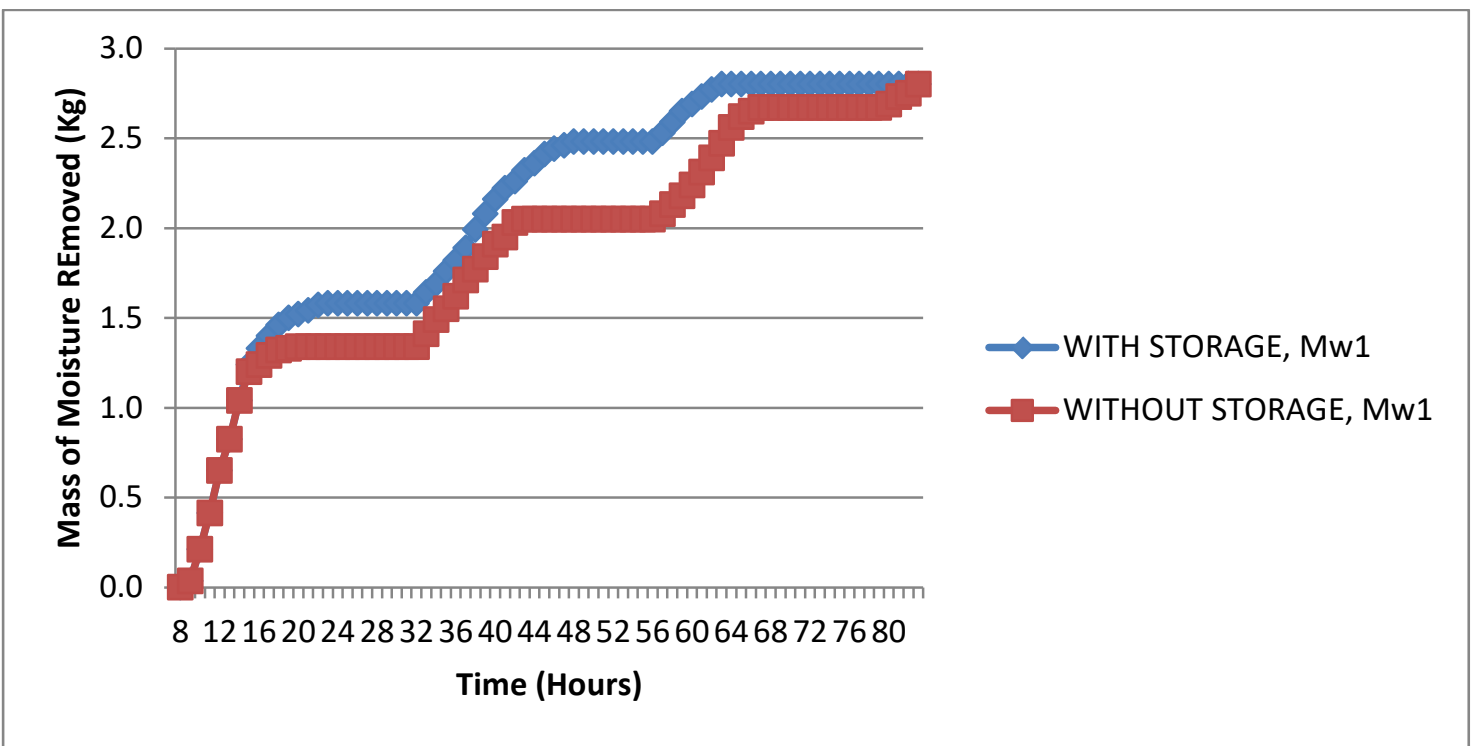

Fig. 10. Variation of predicted moisture removed against drying time on the 16, 17, 18 and 19th of August for solar cabinet dryer with and without heat storage bed for tray 1

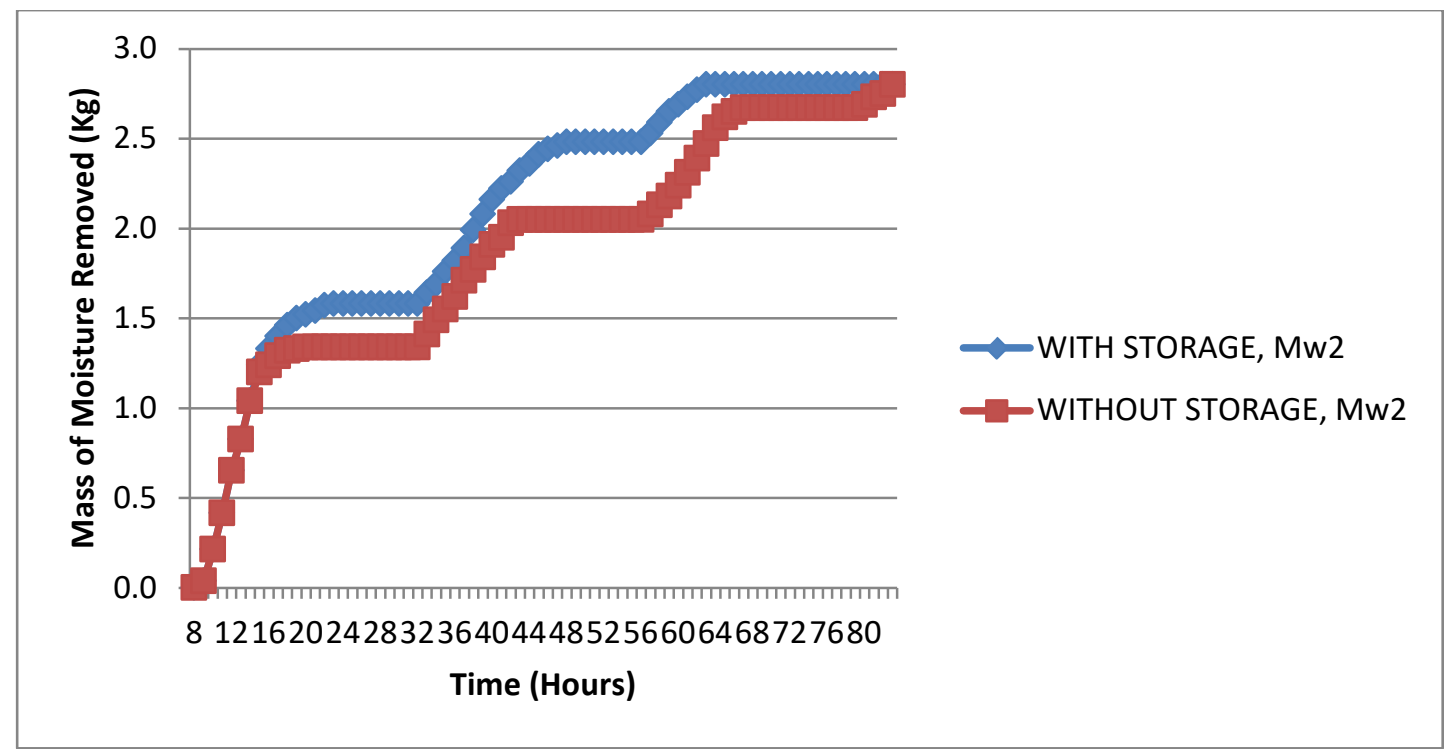

Fig. 11. Variation of predicted moisture removed against drying time on the 16, 17, 18 and 19th of August for solar cabinet dryer with and without heat storage bed for tray 2 


\subsection{Drying Rate}

It is evident that the drying rate is faster at high moisture content (beginning of drying) with a decreasing trend as moisture content of the product reduces. Solar cabinet dryer with thermal storage bed predicted a higher product drying rate for the month of March for trays 1 and 2 as against prediction obtained using solar cabinet dryer without thermal storage medium as depicted in figures 12 and 13. A similar trend drying rate was predicted for both dryer systems for the month of August (Figures 14 and 15). Relatively higher drying rates were obtained for solar cabinet dryer with heat storage medium from 16:00 hours as a result of the supplementary heat in the gravel bed. The average moisture extraction rate obtained in the drying chamber was 0.0759 and $0.0531 \mathrm{~kg}$ per hour in the month of March for solar cabinet dryer with and without thermal storage bed while, the prediction for the month of August was 0.0540 and $0.0374 \mathrm{~kg}$ per hour respectively. For both solar cabinet dryer systems, as the crop gets dried, its drying rate decreased as there is less moisture left to be evaporated from it. The relatively higher average moisture extraction rate exhibited by system with thermal storage bed is attributed to the prolong drying through the heat stored. Thus, product being dried in the solar cabinet dryer with thermal storage bed facility attains equilibrium moisture content faster than if dried in system without thermal storage bed.

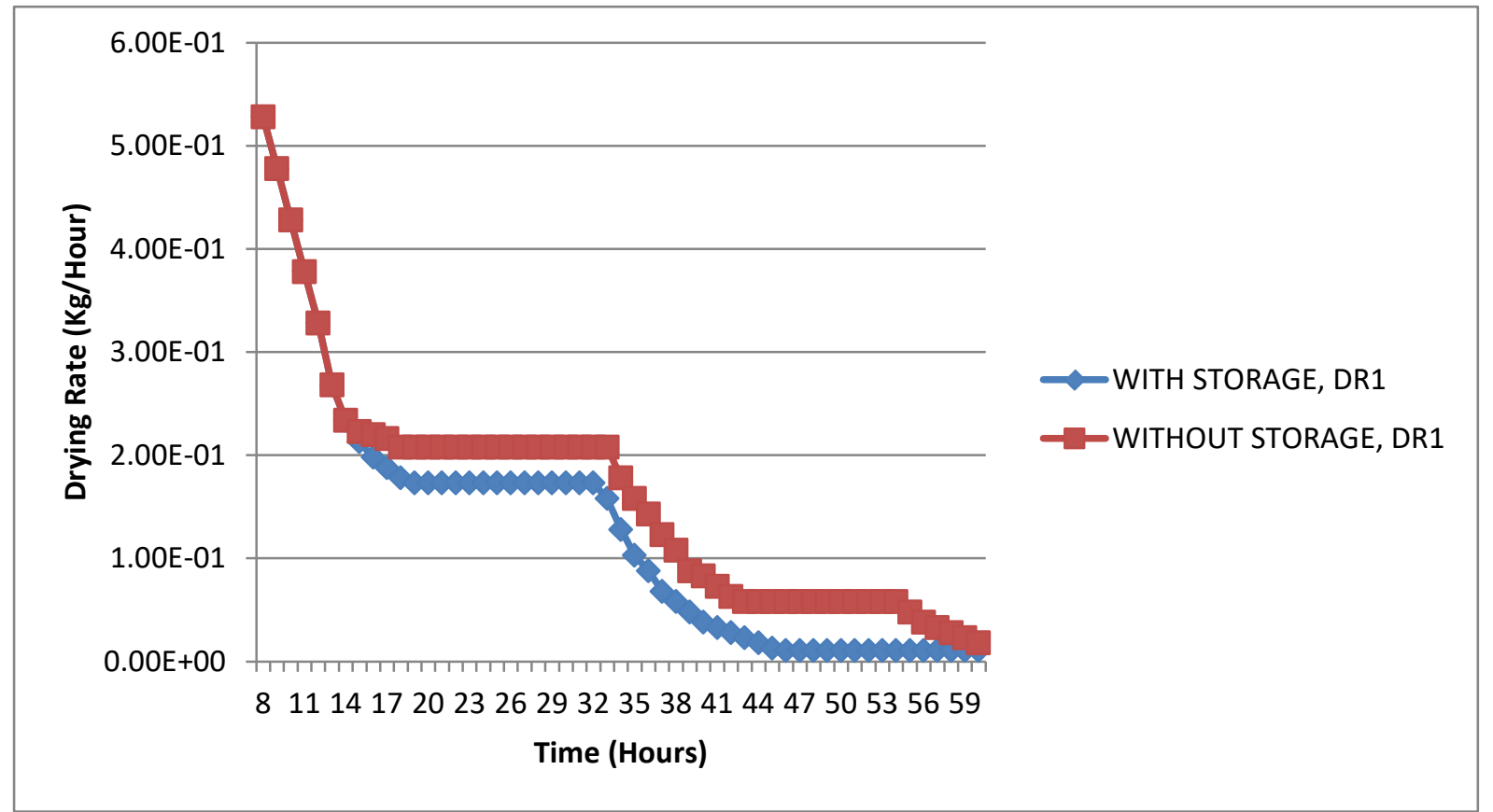

Fig. 12. Variation of predicted drying rate against drying time on the 16, 17 and 18th of March for solar cabinet dryer with and without heat storage bed for tray 1

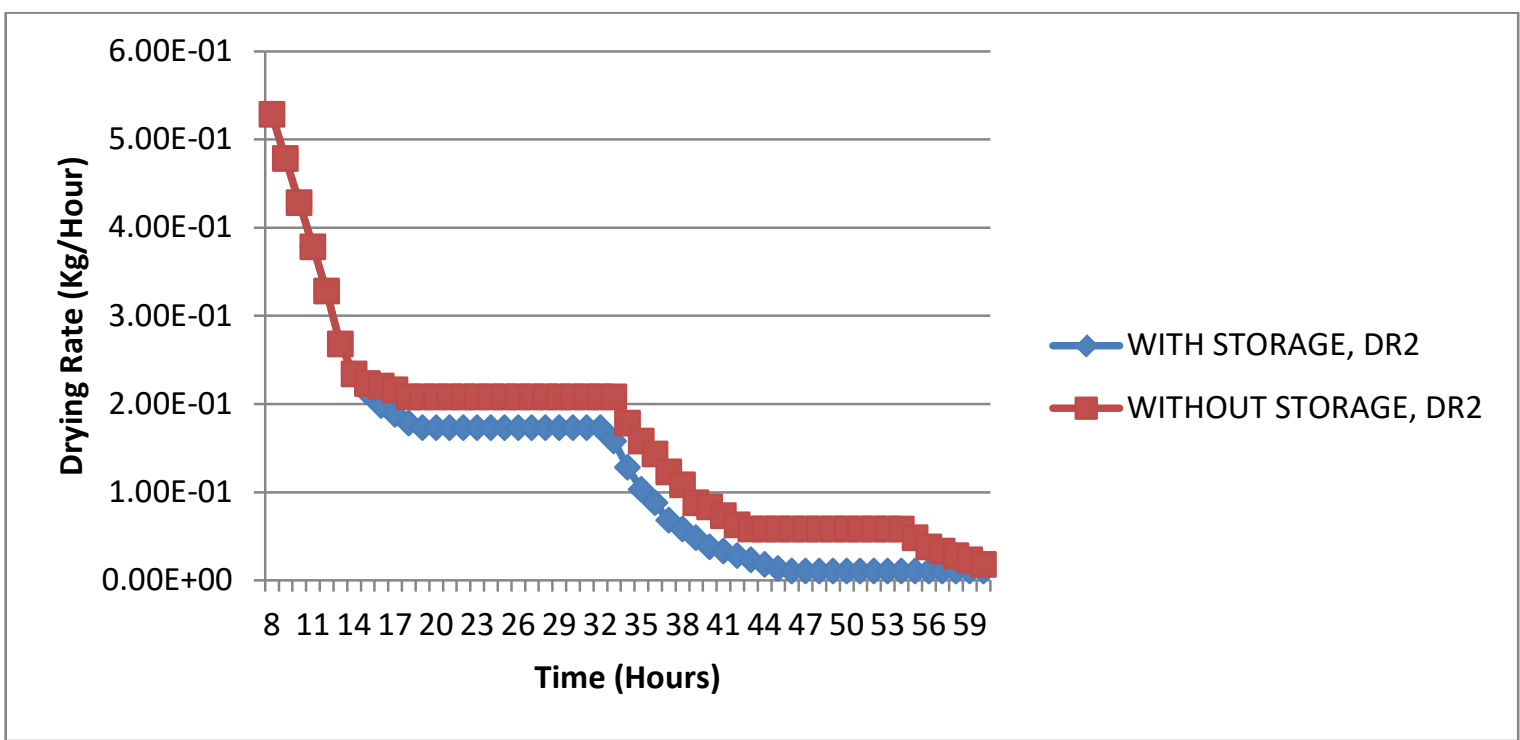

Fig. 13. Variation of predicted drying rate against drying time on the 16, 17 and 18th of March for solar cabinet dryer with and without heat storage bed for tray 2 


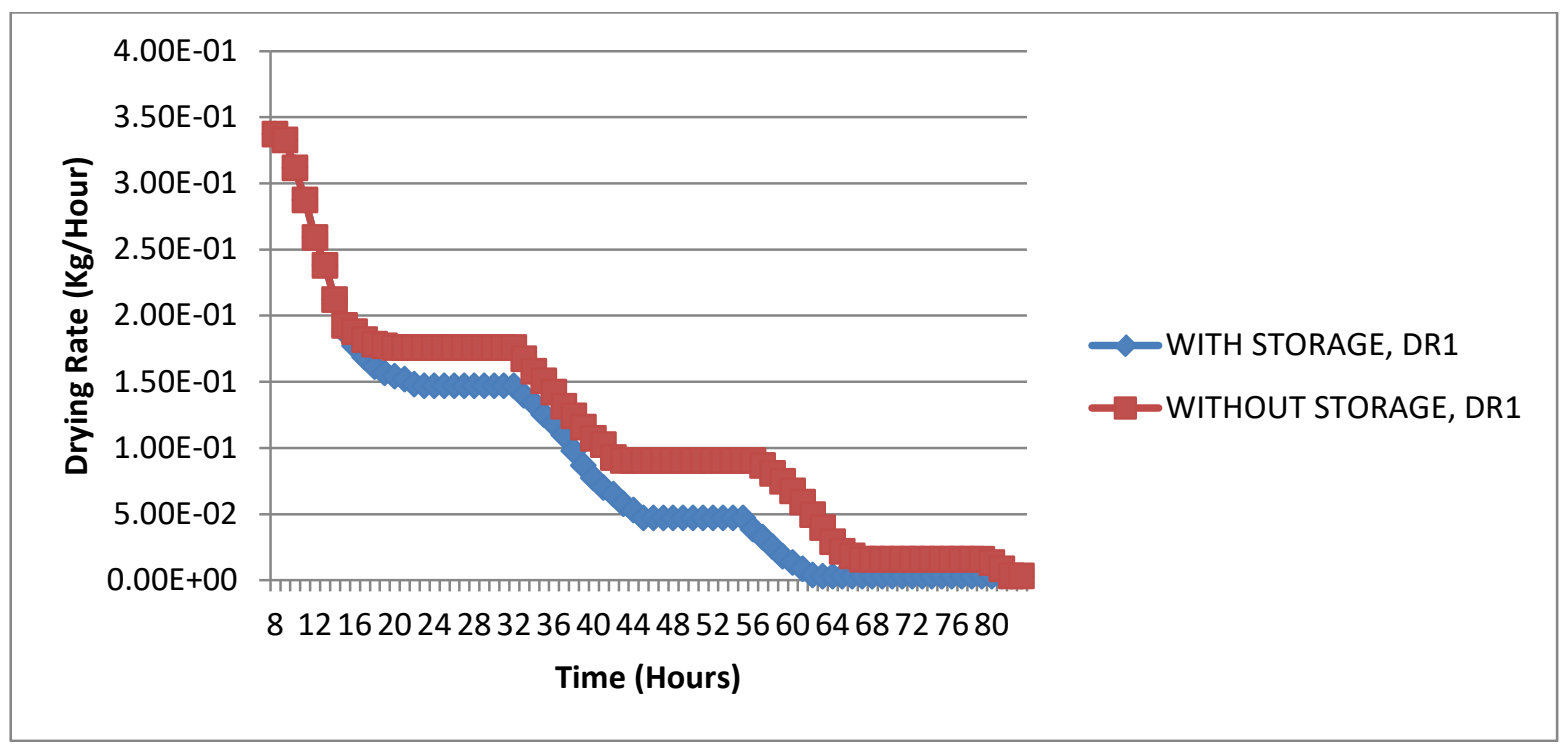

Fig. 14. Variation of predicted drying rate against drying time on the 16, 17, 18 and 19th of August for solar cabinet dryer with and without heat storage bed for tray 1

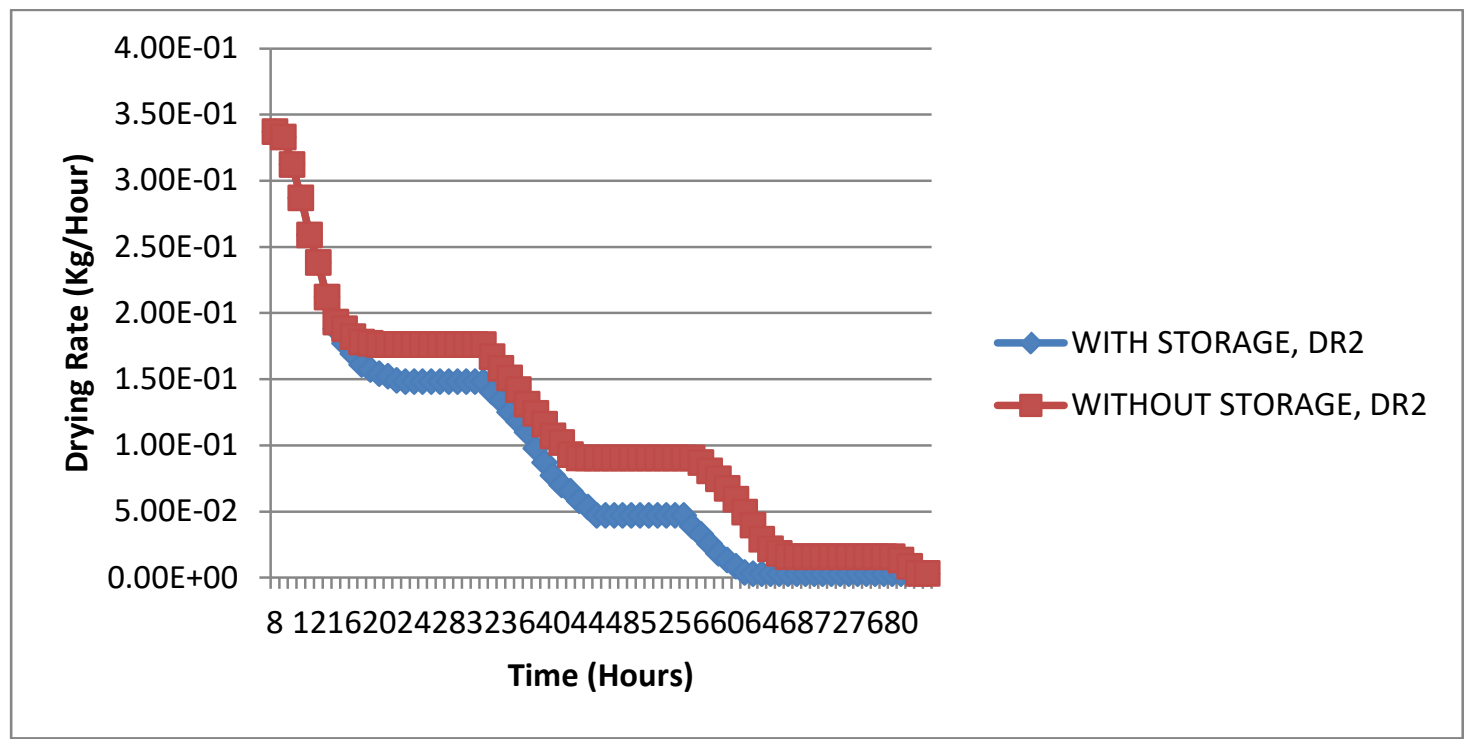

Fig. 15. Variation of predicted drying rate against drying time on the 16, 17, 18 and 19th of August for solar cabinet dryer with and without heat storage bed for tray 2

\subsection{Moisture Content}

As the hot air rises in the drying chamber it picks up moisture from the crop on the trays. This results in reduction of weight (moisture loss) of tomatoes. The predicted moisture content of 3kg of tomatoes (assumed moisture content of 94\%) placed on tray 1 and 2 for solar cabinet dryer incorporated with a thermal storage medium reached 4.50\% (w.b) moisture content in the month of March after 37 hours of drying and 53 hours for solar cabinet dryer without thermal storage bed under similar weather condition (Fig. 16-19). For the month of August, it took 52 hours of drying for dryer with thermal storage bed and 75 hours for similar solar cabinet dryer without thermal storage facility (Figures 16-19). The heat stored in the gravel bed served as supplementary heat and was used for heating the product drying air and thus, decreasing its relative humidity and increasing the capacity of the air to carry away the moisture from the trays during off solar radiation period. 


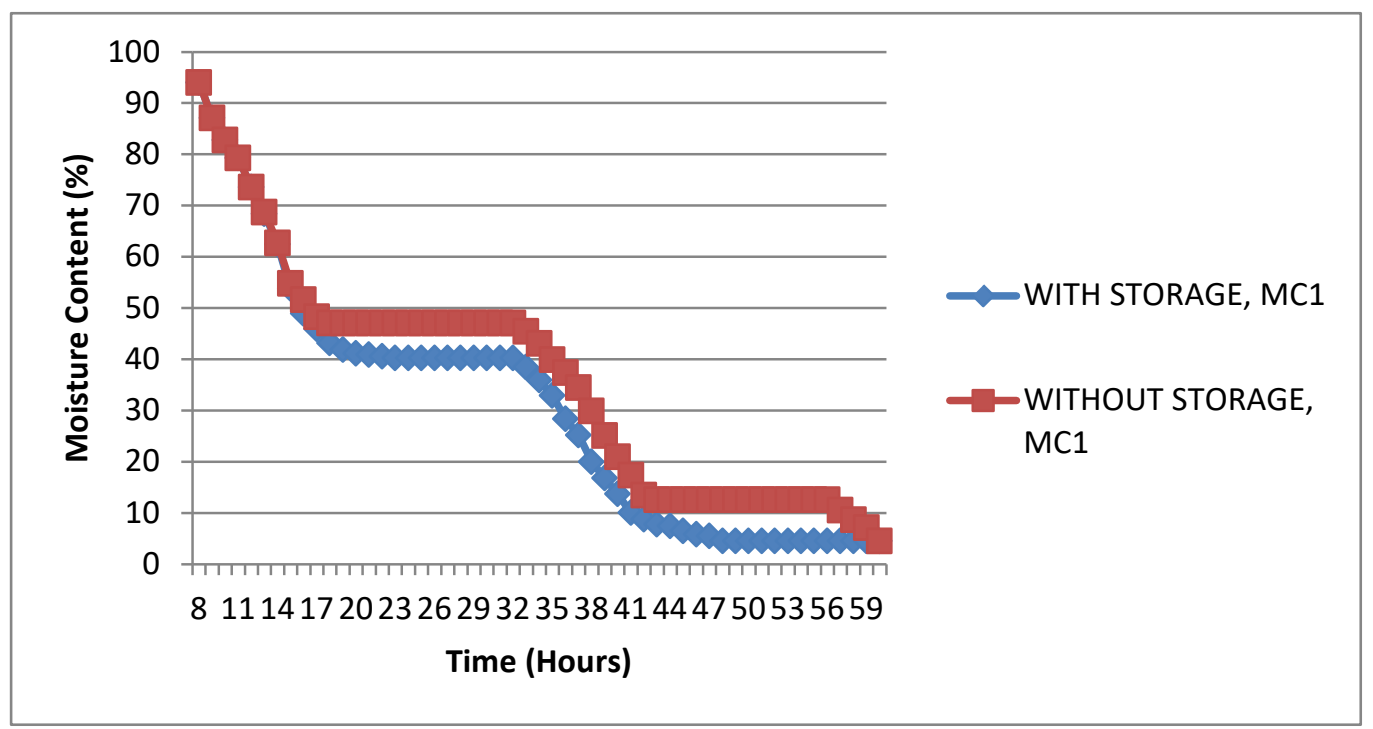

Fig. 16. Variation of predicted moisture content against drying time on the 16, 17 and 18th of March for solar cabinet dryer with and without heat storage bed for tray 1

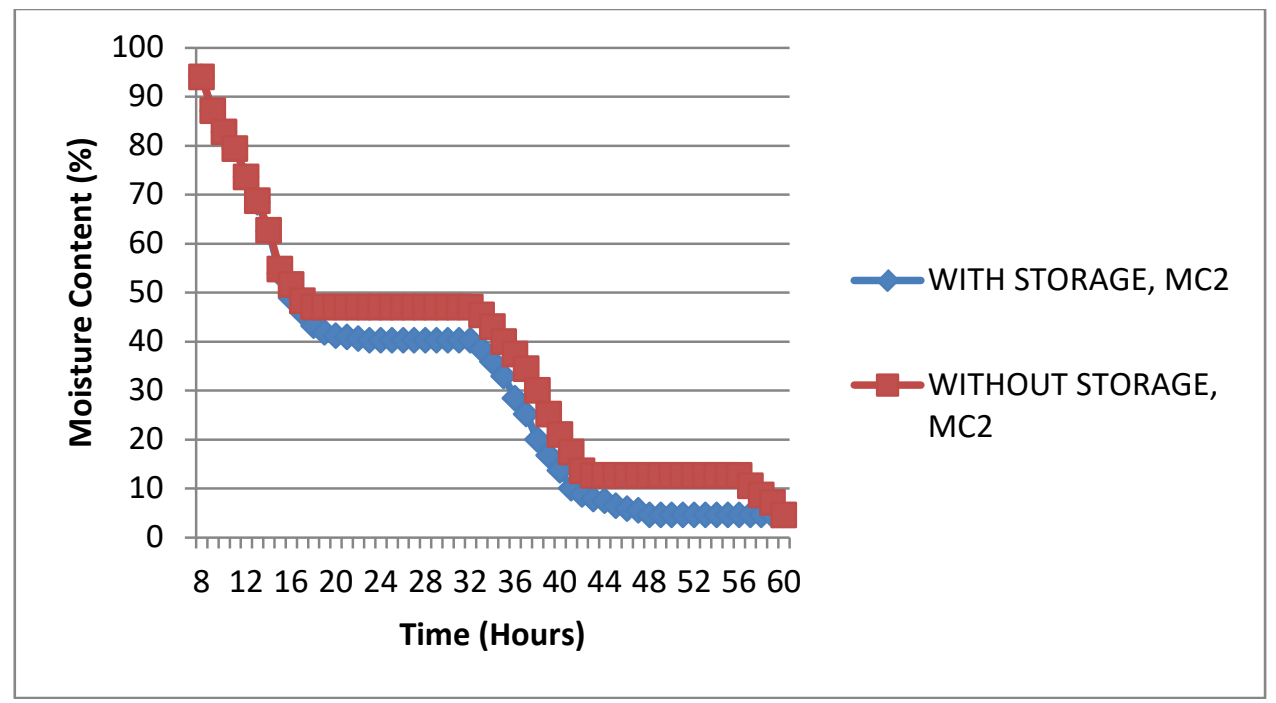

Fig. 17. Variation of predicted moisture content against drying time on the 16, 17 and 18th of March for solar cabinet dryer with and without heat storage bed for tray 2

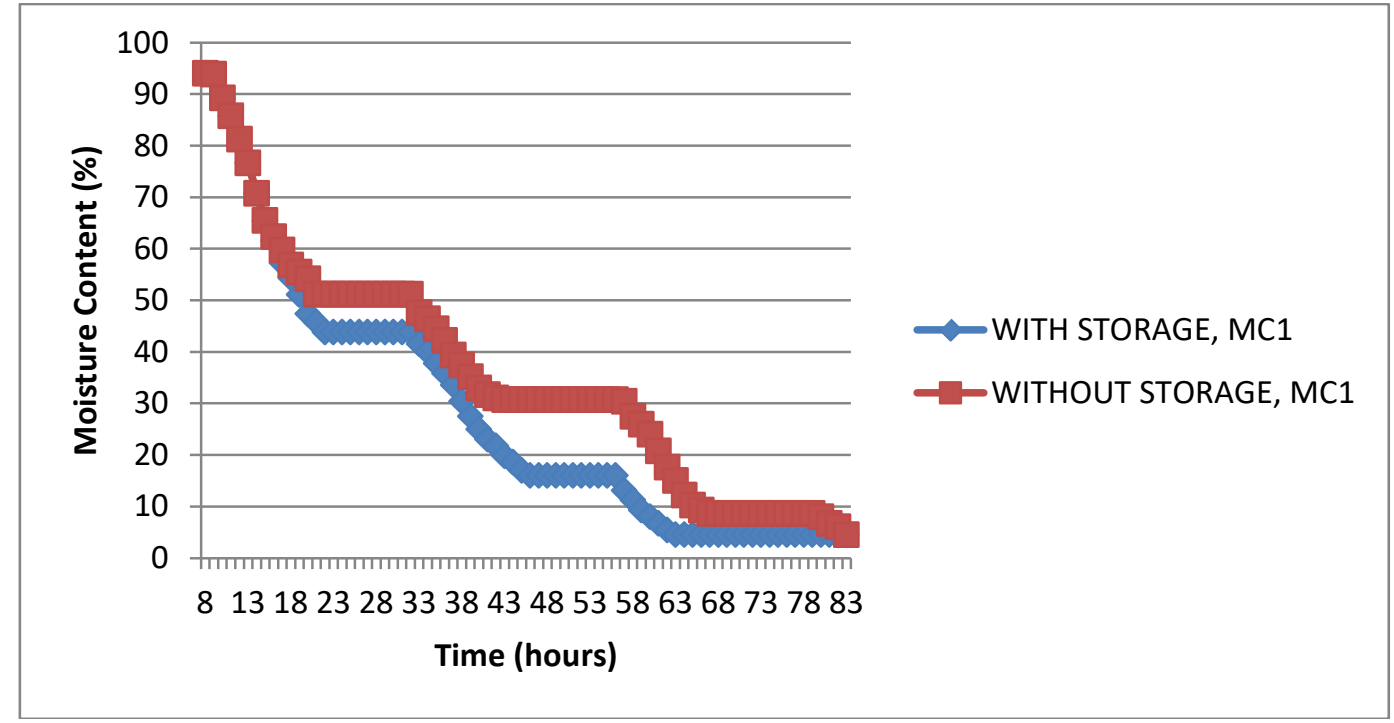

Fig. 18. Variation of predicted moisture content against drying time on the 16,17, 18 and 19th of August for solar cabinet dryer with and without heat storage bed for tray 1 


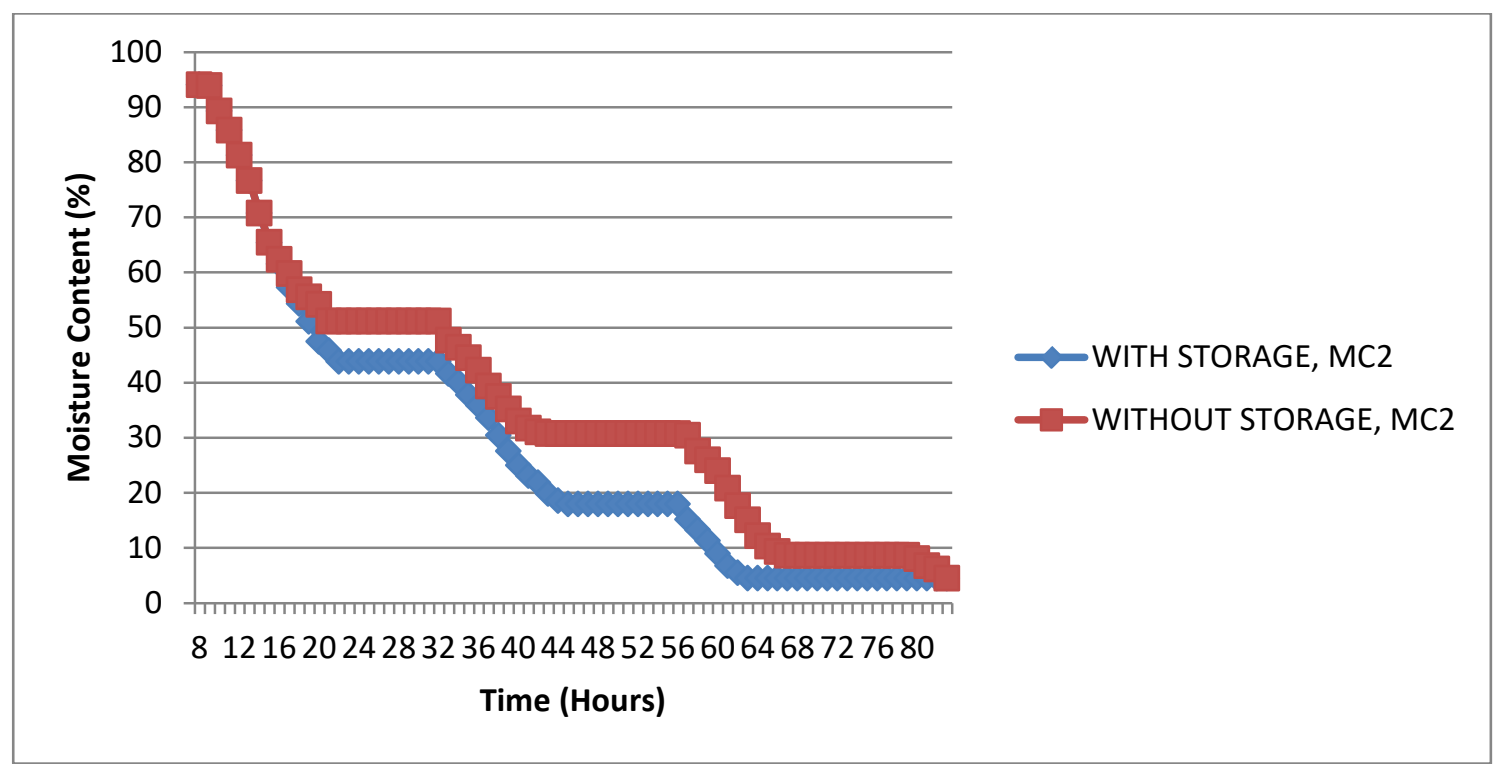

Figure 19: Variation of predicted moisture content against drying time on the 16, 17, 18 and 19th of August for solar cabinet dryer with and without heat storage bed for tray 2

\subsection{Collector Efficiency}

As indicated in figures 20 and 21, the collector efficiency increases as the solar intensity is increased and attained an average peak value at solar intensity of 575 and $1049 \mathrm{~W} / \mathrm{m} 2$ for August and March respectively between the hours of 12:00noon and 2:00pm for day 1. Maximum solar collector efficiency due to introduction of thermal storage bed was found to be 50.12 and $45.83 \%$ in the month of March and August respectively, and was slightly lower compared to 43.85 and 37.60\% obtained for solar cabinet dryer system without heat storage bed (Fig. 20 and 21). The solar cabinet dryer with the thermal storage material gives up to $6 \%$ higher collector efficiency compared to that without thermal storage material. The thermal properties of the gravels have significant influence on the performance of the solar collector. The relatively higher solar collector efficiency exhibited by solar cabinet dryer with thermal storage bed is attributed to the significant retention and utilization of heat that would be lost through the absorber back plate. However, this is contrast to the work of Saravanakumar et al., (2012) who obtained lower collector efficiency using gravel as thermal storage medium underneath collector absorber plate compared to similar collector with non inclusion of sensible heat storage material beneath it under same weather condition.

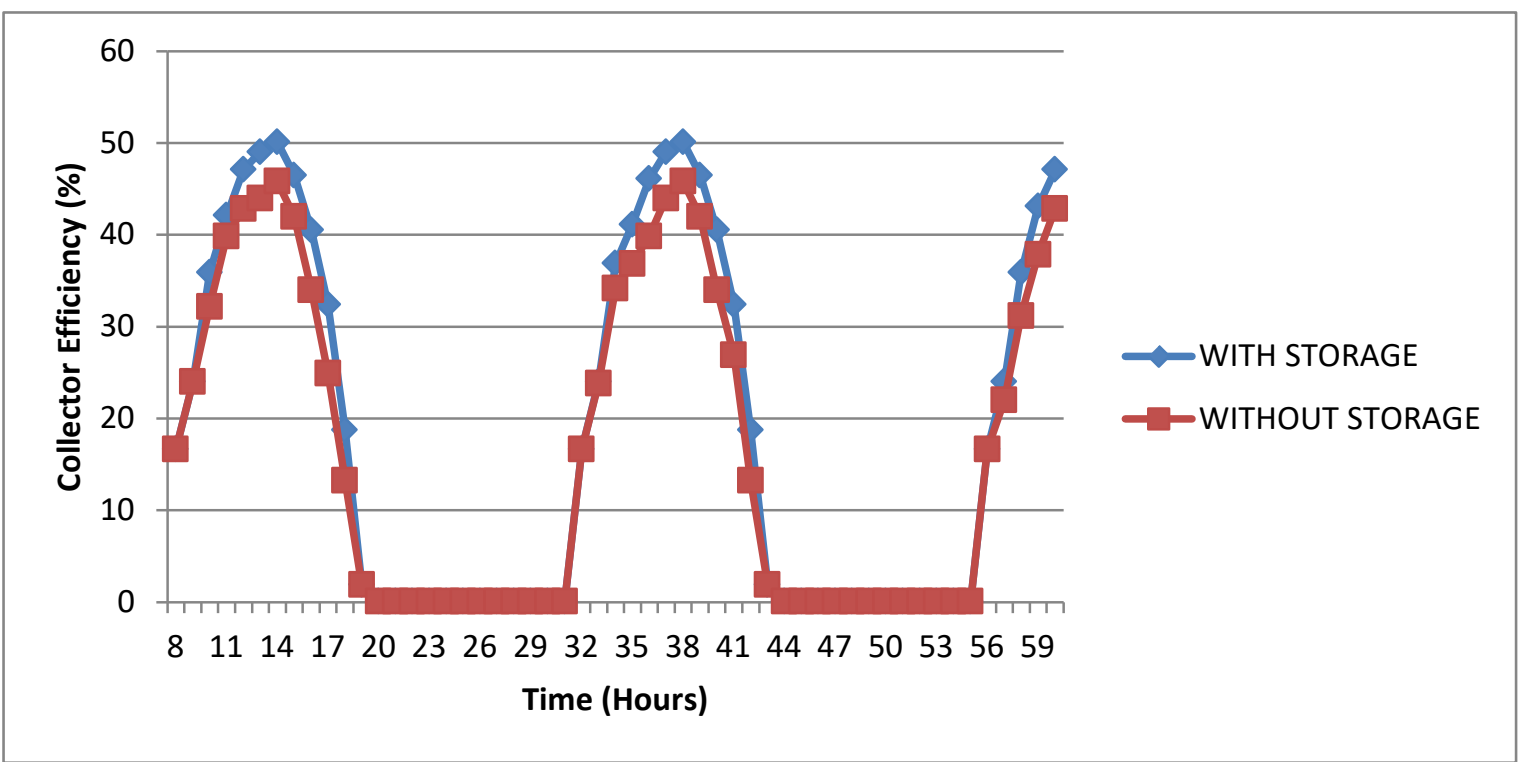

Fig. 20. Variation of predicted collector efficiency against drying time on the 16, 17 and 18th of March for solar cabinet dryer with and without heat storage bed. 


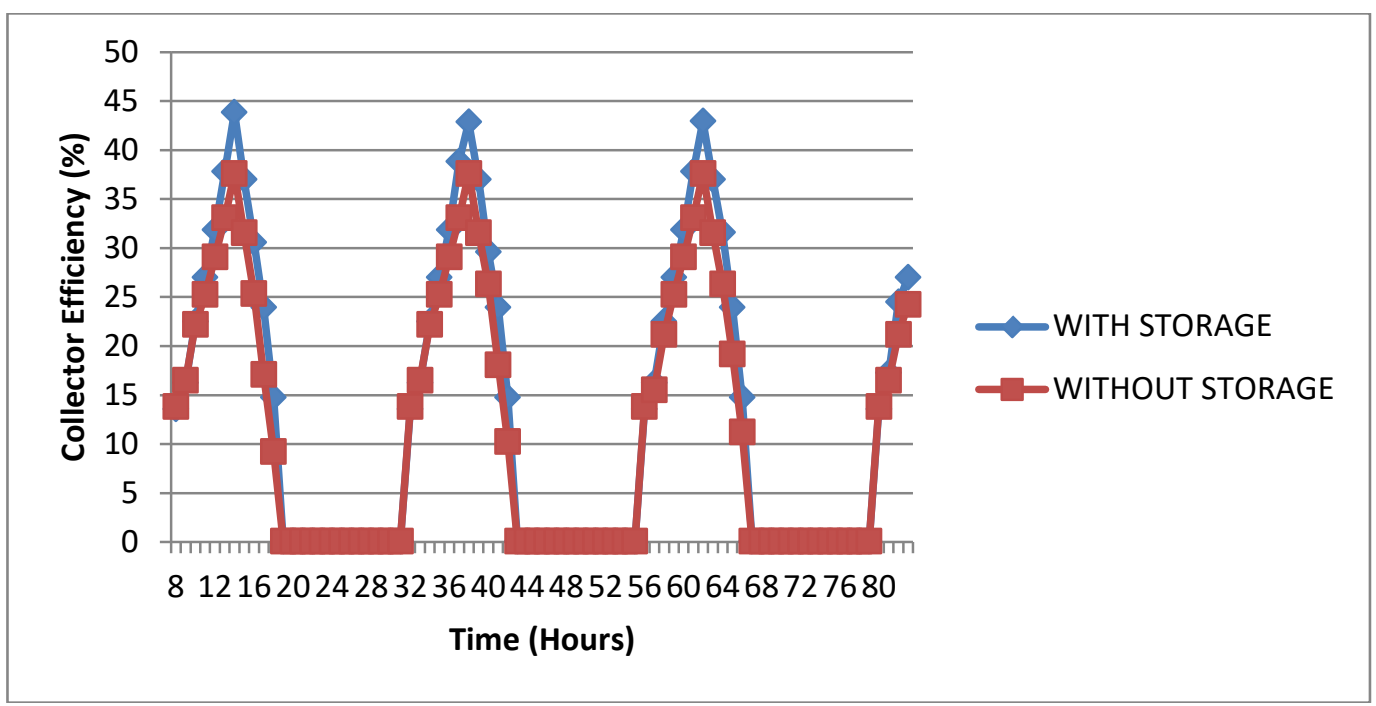

Fig. 21. Variation of predicted collector efficiency against drying time on the 16, 17, 18 and 19th of August for cabinet dryer with and without heat storage bed

\section{Conclusion}

From the results obtained, it can be seen that the solar cabinet dryer integrated with a heat storage bed will be efficient for drying high moisture content crop under hygienic condition compared to the traditional open sun drying method and that without heat storage bed. The maximum predicted product drying air temperature of 48 and $69^{\circ} \mathrm{C}$ were obtained in the month of August and March for non-inclusion of a heat storage bed, $46^{\circ} \mathrm{C}$ and $66^{\circ} \mathrm{C}$ when incorporated with a heat storage bed respectively. The predicted maximum heat storage bed temperatures were 37 and $59.3^{\circ} \mathrm{C}$ for the months of August and March respectively. The system predicted a faster rate of moisture removal using gravels as heat storage medium. The average moisture extraction rate of 0.1124 and $0.0739 \mathrm{~kg}$ per hour in the month of March for solar cabinet dryer with and without heat storage while, the month of August with the least performance had 0.0780 and $0.0669 \mathrm{~kg}$ per hour respectively are in support of gravels as heat storage medium for solar dryers. The predicted maximum solar collector efficiency due to introduction of thermal storage bed was found to be higher in the range of 4$8 \%$ compared as against that without thermal storage bed. In essence, the use of gravels as thermal storage medium in solar dryers as well as the need to minimum cost of materials by adapting a multi-tray cabinet drying system is supported by the model, and should be validated using experimental results. Quit a good number of researchers have reduce the drying time of crops using sensible heat storage bed (Shalaby, 2012; Kamble et al,. 2013; Kamble and Dombale; 2016). Also, TRNSYS simulation has proven to be a valid tool in the development of solar space and water heating applications. There is the need to develop and adequately study a gravel-pit (GP) and or water-gravel pit storage system (WGPS) for a range of operating parameters based on temperature distribution, thermal energy stored, available energy stored in the bed, energy consumption by blower (for active bed), and thermal efficiency of the collector. This will give clear guidelines for using the gravels for large scale solar thermal energy storage for space and water heating applications. The usage of gravels for thermal energy storage that will facilitate heating applications will reduce the consumption rate of fuel-wood, conventional fuels and help preserve the environment.

\section{References}

[1] Garg H.P and Prakash J. Solar Energy: Fundamentals and Applications. First Revised Edition. Tata McGraw Hill Education Private Limited, New Delhi, 2010.

[2] Fellows, P. Guidelines for Small-Scale Fruit and Vegetable Processors, FAO Agricultural Services Bulletin 127, FAO of the United Nations, Rome, 1997.

[3] Centre Bank of Nigeria Annual Report. An annual publication of the Centre Bank of Nigeria, 2017

[4] Gutti B., Kiman S. and Murtala A. M .Solar Dryer: An Effective Tool for Agricultural Products Preservation. Journal of Applied Technology in Environmental Sanitation. 2(1):31-38, 2012.

[5] Shalaby S. M. Effect of Using Energy Storage Material in an Indirect-mode Forced Convection Solar Dryer on the Drying Characteristics of Grapes. Journal of Medical and Bioengineering (JOMB). 1(1): 56-58, 2012

[6] Shariah AM, Shialabi B. Optimal Design for a Thermosyphon Solar Water Heater. Renewable Energy, 11:351-361, 1997

[7] Joshua Ibrahim, Aoandona Kwaghger and Shehu Mohammed Sani. Modeling and Simulation of a Thermosiphon Solar Water Heater in Makurdi using Transient System Simulation. International Journal of Scientific and Engineering Research, IJSER,10(12):451-459, 2019

[8] Johnson Z. S, Pam G. Y and Peter K. M. Conceptual Design and Performance Prediction of a Thermosyphon Solar Water Heating System using TRNSYS. International Journal of Engineering Research and Technology, IJERT, 3 (10):420-428, 2014.

[9] Johnson, Z. S, Yohanna N. S and Peter K.M (2015). Performance Simulation of an Active Solar Water Heating System under the Weather of Zaria Using TRNSYS. International Journal of Scientific and Engineering Research, 6(3):416-422, 2015. 
[10] Harikrishnan P. V and Richu Zachariah. International Journal of Engineering Sciences and Research Technology Computational Studies on Performance of A Mixed Mode Solar Dryer With Thermal Storage, IJESRT, 235-243, 2016

[11] Gideon Ayuba Duvuna. Modeling and Simulation of Experimental Parameters of An Active Solar Water Heating System for Clinical Applications. Unpublished PhD Seminar II, Abubakar Tafawa Balewa University, Bauchi, 2016

[12] Youcef-Ali S., Messaoudi H., Desmons J.Y., Abene A and Le Ray M. Determination of the Average Coefficient of Internal Moisture Transfer during the Drying of a Thin Bed of Potato Slices. Journal of Food Engineering. 48(2):95-101, 2001

[13] Atkilt Mulu Gebrekida. Performance of an Enhanced Solar Drier Integrated with Heat Storage System for Fruits and Vegetables Drying. Unpublished M. Sc Thesis in Energy Technology, Mekelle University, Ethiopian Institute of Technology, Mekelle, 2013.

[14] Onigbogi I.O, Sobowale, S. S and Ezekoma, O.S. Design, Construction and Evaluation of a Small Scale Solar Dryer. Journal of Engineering and Applied Science, 4: 8-21, 2012

[15] Kamble A. K and Dombale R. L. Studies on Natural convection solar Cabinet Dryer Coupled with Heat Storage for Drying Tomato Slices. International Journal of Research in Engineering, Science and Technologies, IJREST, 1(6):6-12, 2016.

[16] Sengar S. H, Mohod A. G and Khandetod Y.P. Experimental Evaluation of Rotary Solar Dryer for Kokam Fruit. Journal of Agricultural Science. 2(3):62-69, 2012.

[17] Misra, M. K and Brooker D. B. (1980). Thin-Layer Drying and Rewetting Equations for Shelled Yellow Corn. Transactions of the ASAE, 1254-1260, 1980.

[18] Gunasekaran, S., and Thompson, T. L. Optimal energy management in grain drying. CRC Critical Reviews in Food Science and Nutrition, 25(1):1-48, 1986

[19] Benjamin Ternenge Abur and Muhammad Hadi Ibrahim. Life Cycle Cost Analysis of a Multi-Tray Solar Dryer with Thermal Energy Storage Bed. 7th Annual and International Conference of the Renewable and Alternative Energy Society of Nigeria, RAESON held at Federal University of Technology, Akure, 26th_30th April, 2017

[20] Saravanakumar P. T, Mayilsamy K and Mohanraj M. Numerical Study and Thermal Performance of the Flat Plate Solar Air Heaters With and Without Thermal Storage. ARPN Journal of Engineering and Applied Sciences, 7(4):467-471, 2012.

[21] Kamble A. K, Pardeshi I. L, Singh P.L and Ade G.S. Drying of chilli using solar cabinet dryer coupled with gravel bed heat storage system. Journal of Food Research and Technology, 1(2):87-94, 2013

[22] Kamble A. K and Dombale R. L. Studies on Natural convection solar Cabinet Dryer Coupled with Heat Storage for Drying Tomato Slices. International Journal of Research in Engineering, Science and Technologies, IJREST, 1:(6):6-12, 2016

[23] Gideon Ayuba Duvuna. Validation of An Active Solar Water Heating System for Clinical Applications. Unpublished PhD Seminar IV, Abubakar Tafawa Balewa University, Bauchi, 2017

\section{Authors’ Profiles}

Benjamin Ternenge Abur obtained his B.Eng, M.Eng at Bayero University Kano, Nigeria. A Registered Engineer and Lecturer in the Department of Mechanical/Production Engineering, Abubakar Tafawa Balewa University, Bauchi, Nigeria where he is studying for his $\mathrm{PhD}$ in Mechanical Engineering. His scientific area of interest is renewable energy.

Habou Dandakouta received his B.Eng, M.Eng and $\mathrm{PhD}$ in Mechanical Engineering from Abubakar Tafawa Balewa University, Bauchi, Nigeria. A Registered Mechanical Engineer and a Professor of Energy Studies in the Department of Mechanical/Production Engineering, Abubakar Tafawa Balewa University, Bauchi, Nigeria. University Faculty of Engineering Representative for Post-graduate Studies. Currently, the Head Automotive Engineering Department. His research interests are in solar energy, wind energy, bio-fuels and thermo-fluids.

Bello A. Adisa studied for his B.Eng, M.Eng and PhD in Mechanical Engineering from the prestigious Abubakar Tafawa Balewa University, Bauchi-Nigeria. A Professor of Energy Studies and former Head of Mechanical/Production Engineering Department at Abubakar Tafawa Balewa University, Bauchi, Nigeria. Former National Chairman and a Fellow of the Nigerian Institution of Mechanical Engineers (FNIMechE). Also a member of ASME as well as a Fellow, Nigeria Society of Engineers (FNSE). He is at present, overseeing activities at the Centre for Industrial Studies as the Director. His technical research interests are in energy.

Robinson I. Ejilah is an Associate Professor of Energy Studies in the Department of Mechanical/Production Engineering, Abubakar Tafawa Balewa University, Bauchi-Nigeria where he studied for his PhD in Mechanical Engineering. A former National Chairman, Nigerian Institution of Mechanical Engineers, and a Fellow (FNIMechE) of the institution. His area of interest is renewable energy systems.

How to cite this paper: Benjamin Ternenge Abur, Habou Dandakouta, Adisa A. B and Ejilah R.I., " Modeling and Simulation of an Indirect Natural Convection Solar Dryer with Thermal Storage Bed ", International Journal of Engineering and Manufacturing (IJEM), Vol.10, No.4, pp.24-42, 2020. DOI: 10.5815/ijem.2020.04.03 


\section{Nomenclature}

A cross sectional area of the gravel bed, $\mathrm{m}^{2}$ $A_{C}$ collector area, $\mathrm{m}^{2}$

$A_{p}$ product area, $\mathrm{m}^{2}$

$A_{v}$ surface area of the cylindrical chimney, $\mathrm{m}$

$C_{c}$ specific heat capacity of glass cover, $\mathrm{kJ} / \mathrm{kgK}$

$C_{p}$ specific heat capacity of the absorber plate, $\mathrm{kJ} / \mathrm{kgK}$

$C_{p a}$ specific heat of the working fluid, $\mathrm{kJ} / \mathrm{kgK}$

$c_{p r}$ specific heat capacity of gravels, $\mathrm{kJ} / \mathrm{kgK}$

$D_{c}$ product thickness, $\mathrm{m}$

$D_{R}$ drying rate, $\mathrm{kg} /$ hour

$\mathrm{g}$ acceleration due to gravity, $\mathrm{m} / \mathrm{s}^{2}$.

$\mathrm{h}$ height of the chimney, $\mathrm{m}$

$h_{f g}$ latent heat of vaporization of water, $\mathrm{J} / \mathrm{kg}$

$h_{f g 1}$ latent heat of vaporization of product on tray 1 ,

$\mathrm{kJ} / \mathrm{kg}$

$h_{f g 2}$ latent heat of vaporization of crop on tray 2,

$\mathrm{kJ} / \mathrm{kg}$

$H_{a}$ Humidity ratio, $\mathrm{kg} / \mathrm{kg}$

$h_{a}$ heat transfer coefficient between the ambient and the glass cover, $\mathrm{W} / \mathrm{m}^{2} \mathrm{~K}$

$h_{f c}$ heat transfer coefficient between the glass cover and working fluid, $\mathrm{W} / \mathrm{m}^{2} \mathrm{~K}$

$h_{f p}$ heat transfer coefficient between the absorber plate and working fluid, $\mathrm{W} / \mathrm{m}^{2} \mathrm{~K}$

$h_{r}, a_{c}$ radiative heat transfer coefficient between the glass cover and the ambient, $\mathrm{W} / \mathrm{m}^{2} \mathrm{~K}$.

$h_{r}, c_{p}$ radiative heat transfer coefficient between the glass cover and the absorber plate, $\mathrm{W} / \mathrm{m}^{2} \mathrm{~K}$ $\mathrm{i}=1,2,3,4,5$ etc represents different layers of drying

I solar intensity, $\mathrm{W} / \mathrm{m}^{2}$

$m_{a}$ mass flow rate of fluid per unit width, $\mathrm{kg} / \mathrm{s}$

$M_{e}$ equilibrium moisture content, \%

$M_{f}$ instantaneous moisture content of the crop, \%

$m_{p}$ dryer capacity per batch, $\mathrm{kg}$

$M_{i}$ initial moisture content of the crop, \%

$m_{r}$ mass of the gravels, $\mathrm{kg}$

$M_{r}$ moisture ratio (dimensionless)

$m_{w}$ water removed per $\mathrm{kg}$ of the air, $\mathrm{kg}$

$m_{w 1}$ mass of water removed per kg of air on tray 1 , $\mathrm{kg}$

$m_{w 2}$ mass of water removed per kg of air on tray 2, $\mathrm{kg}$

$\mathrm{P}$ perimeter of the bed, $\mathrm{m}$
$Q$ amount of energy required for the drying process, $\mathrm{kJ}$

$\mathrm{r}$ radius of the chimney, $\mathrm{m}$

$R_{t}$ thickness of gravel heat storage material, $\mathrm{m}$

$t_{d}$ drying time, hours

$\mathrm{T}$ drying air temperature at the drying tray, ${ }^{\circ} \mathrm{C}$

$T_{1}$ initial temperature of the given product on tray, ${ }^{\circ} \mathrm{C}$

$T_{2}$ final temperature of the given product on tray, ${ }^{\circ} \mathrm{C}$

$T_{a}$ solar air heater inlet temperature

$T_{a 1}$ product drying temperature on tray $1,{ }^{\circ} \mathrm{C}$

$T_{a 2}$ product drying temperature on tray $2,{ }^{\circ} \mathrm{C}$

$T_{c}$ glass cover temperature, ${ }^{\circ} \mathrm{C}$

$T_{c h}$ drying chamber exit temperature, ${ }^{\circ} \mathrm{C}$

$T_{p}$ absorber plate temperature, ${ }^{\circ} \mathrm{C}$

$T_{p r}$ maximum allowable temperature of the dried product, ${ }^{\circ} \mathrm{C}$

$T_{r}$ gravel bed temperature, $\mathrm{K}$

$\mathrm{U}$ loss coefficient from the rock bed to the environment, $\mathrm{W} / \mathrm{m}^{2} \mathrm{~K}$

$u_{b}$ bottom overall heat loss coefficient

$v_{a}$ average wind-speed of location, $\mathrm{m} / \mathrm{s}$

$\mathrm{V}$ volumetric air flow rate, $\mathrm{m}^{3} / \mathrm{s}$

$V_{a}$ air flow rate, $\mathrm{m}^{3} / \mathrm{s}$

$V_{s}$ volume of the storage material, $\mathrm{m}^{3}$

\section{Greek Symbols}

$\Delta T$ temperature elevation of the gravel bed, ${ }^{\circ} \mathrm{C}$

$\eta_{s}$ efficiency of gravel bed, \%

$\rho_{o}$ air density at ambient temperature, $\mathrm{kg} / \mathrm{m}^{3}$

$\rho_{a}$ average air density at the drying temperature, $\mathrm{kg} / \mathrm{m}^{3}$

$\alpha_{c}$ absorptivity of the glass cover

$\rho_{a}$ density of air, $\mathrm{kg} / \mathrm{m}^{3}$

$\rho_{r}$ density of gravels, $\mathrm{kg} / \mathrm{m}^{3}$

$\rho_{c}$ product density, $\mathrm{kg} / \mathrm{m}^{3}$

$\rho_{c}$ density of glass cover, $\mathrm{kg} / \mathrm{m}^{3}$

$\delta_{c}$ thickness of glass cover, $\mathrm{m}$

$\varepsilon_{c}$ emissivity of glass cover

$\varepsilon_{p}$ is emissivity of absorber plate

$\rho_{p}$ density of the absorber plate, $\mathrm{kg} / \mathrm{m}^{3}$

$\delta_{p}$ thickness of the absorber plate, $\mathrm{m}$

$\alpha_{p}$ absorptivity of the absorber plate 